\title{
Shuttle Damage/Repair from the Perspective of Hypersonic Boundary Layer Transition - Experimental Results
}

\author{
Thomas J. Horvath*, Scott A. Berry", N. Ronald Merski", Karen T. Berger ${ }^{*}$ \\ Gregory M. Buck*, Derek S. Liechty* \\ NASA Langley Research Center, Hampton, Virginia, 23681 \\ and \\ Steven P. Schneider \\ Purdue University, West LaFayette, Indiana, 47907
}

\begin{abstract}
$\underline{\text { Abstract }}$
An overview is provided of the experimental wind tunnel program conducted at the NASA Langley Research Center Aerothermodynamics Laboratory in support of an agency-wide effort to prepare the Shuttle Orbiter for Return-to-Flight. The effect of an isolated protuberance and an isolated rectangular cavity on hypersonic boundary layer transition onset on the windward surface of the Shuttle Orbiter has been experimentally characterized. These experimental studies were initiated to provide a protuberance and cavity effects database for developing hypersonic transition criteria to support on-orbit disposition of thermal protection system damage or repair. In addition, a synergistic experimental investigation was undertaken to assess the impact of an isolated mass-flow entrainment source (simulating pyrolysis/outgassing from a proposed tile repair material) on boundary layer transition. A brief review of the relevant literature regarding hypersonic boundary layer transition induced from cavities and localized mass addition from ablation is presented. Boundary layer transition results were obtained using 0.0075-scale Orbiter models with simulated tile damage (rectangular cavities) of varying length, width, and depth and simulated tile damage or repair (protuberances) of varying height. Cavity and mass addition effects were assessed at a fixed location $(x / L=0.3)$ along the model centerline in a region of near zero pressure gradient. Cavity length-to-depth ratio was systematically varied from 2.5 to 17.7 and length-to-width ratio of 1 to 8.5. Cavity depth-to-local boundary layer thickness ranged from 0.5 to 4.8. Protuberances were located at several sites along the centerline and port/starboard attachment lines along the chine and wing leading edge. Protuberance height-to-boundary layer thickness was varied from approximately 0.2 to 1.1. Global heat transfer images and heating distributions of the Orbiter windward surface using phosphor thermography were used to infer the state of the boundary layer (laminar, transitional, or turbulent). Test parametrics include angles-of-attack of 30 deg and 40 deg, sideslip angle of 0 deg, freestream Reynolds numbers from $0.02 \times 10^{6}$ to $7.3 \times 10^{6}$ per foot, edge-to-wall temperature ratio from 0.4 to 0.8 , and normal shock density ratios of approximately 5.3, 6.0, and 12 in Mach 6 air, Mach 10 air, and Mach $6 \mathrm{CF}_{4}$, respectively. Testing to simulate the effects of ablation from a proposed tile repair concept indicated that transition was not a concern. The experimental protuberance and cavity databases highlighted in this report were used to formulate boundary layer transition correlations that were an integral part of an analytical process to disposition observed Orbiter TPS damage during STS114.
\end{abstract}

\footnotetext{
* Aerothermodynamics Branch, Research and Technology Directorate, NASA LaRC.

$\downarrow$ Professor, Purdue University, School of AAE, Associate Fellow, AIAA.
} 


\section{$\underline{\text { Nomenclature }}$}

$\beta \quad$ blowing coefficient (see p. 18)

D cavity depth

M Mach number

Re unit Reynolds number $(1 / \mathrm{ft})$

$\mathrm{p}$ pressure (psi)

$\mathrm{T}$ temperature $\left({ }^{\circ} \mathrm{R}\right)$

$\mathrm{X} \quad$ longitudinal distance from the nose (in)

L model reference length from nose to body-flap hinge line (9.7 in) or cavity length

$\mathrm{k}$ roughness element height (in)

$\alpha \quad$ model angle of attack (deg)

$\delta \quad$ boundary layer thickness (in)

$\theta \quad$ momentum thickness (in)

$\mathrm{Re}_{\theta} \quad$ momentum thickness Reynolds number

$\mathrm{h}$ heat transfer coefficient $\left(\mathrm{lbm} / \mathrm{ft}^{2}-\mathrm{sec}\right)$

$=\mathrm{q} /\left(\mathrm{H}_{\mathrm{aw}}-\mathrm{H}_{\mathrm{w}}\right)$ where $\mathrm{H}_{\mathrm{aw}}=\mathrm{H}_{\mathrm{t} 2}$

$\mathrm{h}_{\mathrm{F}-\mathrm{R}} \quad$ reference coefficient using Fay-Ridell calculation to stagnation point of a sphere $\left(\mathrm{lbm} / \mathrm{ft}^{2}-\mathrm{sec}\right)$

$\mathrm{q}$ heat transfer rate $\left(\mathrm{BTU} / \mathrm{ft}^{2}-\mathrm{sec}\right)$

$\mathrm{H}$ enthalpy (BTU/lbm)

sccm standard cubic centimeters per minute

Subscripts

$\infty \quad$ freestream static conditions

t1 reservoir conditions

t2 stagnation conditions behind normal shock

e local edge condition

aw adiabatic wall

w model surface

tr transition onset

inc incipient

eff effective

\section{Introduction}

After the release of the Columbia Accident Investigation Board's (CAIB) final report ${ }^{1}$ in August 2003, an Entry Aeroheating Panel Working Group led by NASA Johnson Space Center was formed to implement the CAIB recommendations specific to the aerothermodynamic assessment of thermal protection system (TPS) damage and repair. Recommendation 3.8.2 requested that NASA develop and maintain physics based computer models to evaluate thermal protection system damage.... and to establish impact damage thresholds that would trigger corrective action such as on-orbit inspection and repair, when indicated. Several months later, in support of Discovery's Return-To-Flight (RTF), a team of researchers/engineers was assembled to develop one such tool; a predictive capability for a rapid aerothermodynamic assessment to determine the likelihood of high Mach number boundary layer transition (BLT) due to flow disturbances created from TPS damage or repair. Laminar to turbulent flow transition can result in increased heating rates and heating loads on the TPS tiles and in terms of vehicle performance, transition can influence vehicle aerodynamics particularly if it occurs asymmetrically ${ }^{2}$. Earlier than anticipated transition can produce excessive heating resulting in decreased structural subsystem margins and in a worst-case scenario, compromise tile/bond and structural integrity of the Orbiter in areas influenced by turbulent flow. The BLT Prediction Tool is part of a suite of analytic tools to assess the surface heating within, near and downstream of TPS damage sites and the resulting temperatures to the Orbiter substructure.

The existing Shuttle transition criterion prior to RTF was developed and implemented primarily from a ground operations perspective and is used to ensure that transition does not occur too early during entry by regulating roughness (step and gap) tolerances ${ }^{3,4}$ associated with the application/maintenance of approximately 25,000 TPS windward surface tiles prior to launch. Tile impact damage (cavities), loose tile 
gap filler material (protuberances) and/or subsequent repairs (protuberances with/without ablation) represent a significant deviation from this original framework. A new predictive tool for estimating boundary layer transition onset from surface damage/repair was required to allow on-orbit disposition of a compromised TPS. Within a year of the team's inception, an analytic tool based on correlations of wind tunnel data was delivered to the program that identified boundary layer transition thresholds giving managers critical information from which to make decisions to re-enter "as is" or to effect repair. The BLT predictive tool infers the expected time of boundary layer transition during entry based on observed damage and/or repair locations and geometries. While a mechanism-based transition prediction methodology would have been more desirable, the analytic approach the Orbiter engineering community selected (correlations) successfully balanced timely on-orbit disposition capability against RTF cost effectiveness and developmental time constraints. As with any correlation approach, the tool is specific to the Orbiter, and it carries uncertainties due to challenges in extrapolating ground-based measurements to flight. The influence of high Mach number real-gas effects on the transition process remains uncertain. It is recognized, however, that propagation of the transition onset location to the actual disturbance source (i.e., protuberances and cavities) requires high disturbance amplification rates that could diminish differences between ground and flight results.

This paper provides an overview of the experimental program to characterize the influence of damage or repair on Shuttle hypersonic boundary layer transition. The content reflects the status of new wind tunnel testing and analysis that was completed at the time of an RTF Technical Peer Review Panel in March 2005. The correlation methodology used in the BLT predictive tool was developed via the simulation of damage or repairs on scaled Shuttle wind tunnel models, Fig. 1. Collectively, over 1000 wind tunnel runs representing approximately 150 wind tunnel occupancy days and 50 models were required to develop the required BLT database. The following references are five companion papers that summarize the development of an analytic tool to predict transition. Campbell, et al (Ref. 5) provides an overview of a suite of new analytic tools developed to support Orbiter TPS damage/repair assessment. Berry, et al (Ref.6) provides an overview of the integrated effort that was involved in developing a BLT tool for estimating Orbiter transition onset times. Greene, et al (Ref. 7) discusses the Boundary Layer Properties Interpolation tool developed for both the BLT and Tile Damage Cavity Heating tools (see Ref. 5). McGinley, et al (Ref. 8) reviews the historical Orbiter flight data and analysis techniques utilized to calibrate the BLT Tool. Berry, et al (Ref. 9) provides the results of the BLT Tool as applied to the first RTF flight, STS-114.

\section{Motivation and Background}

The Columbia accident investigation ${ }^{1}$ identified the need for a capability to identify and repair damage to the Orbiter TPS. Damage can manifest itself in several forms. Impact damage from ice or foam shed from the external tank during ascent (or from orbital debris) can lead to the formation of localized cavities on the tiled windward surface. Protruding gap fillers are another form of damage. Gap fillers were initially developed to serve as a thermal barrier in areas where localized heating into gaps between adjacent tiles was unacceptable. Successfully implemented as a thermal barrier, gap fillers were later inserted between adjacent tiles to provide cushioning between tiles in areas on the Orbiter found to be susceptible to damage from launch vibrations. Increased gap filler

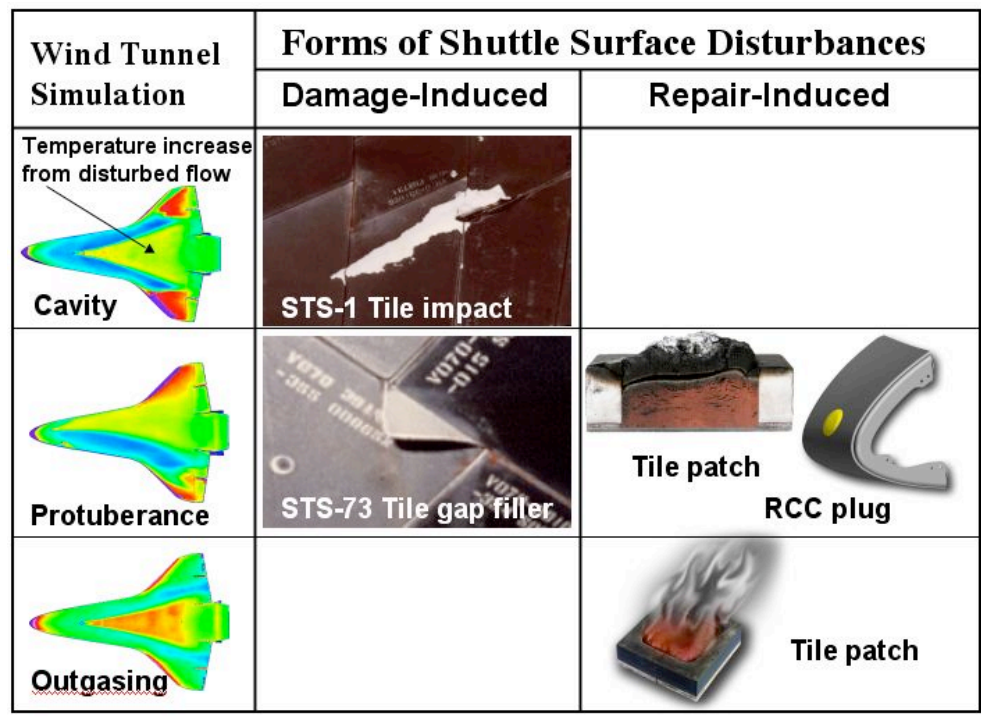

Fig. 1 Transition from damage or repair induced roughness 
use and process deficiencies (e.g., improper gap filler installation and bonding to the inner mold line) occasionally resulted in gap fillers protruding above the nominal outer mold line surface prior to entry.

Similar to protruding gap fillers, most repair concepts presently being pursued embody a form of a protuberance. The allowable surface roughness of the repair would be determined by a criteria based upon the earliest allowable onset of transition. In the case of debris impact with a wing leading edge Reinforced Carbon-Carbon (RCC) panel, the resulting damage could be potentially repaired using a plug concept (Fig. 1 ), which will create steps (protuberances) on the surface.

Should the predicted local heating environment within a tile cavity necessitate a repair, an astronaut would have executed a space walk to apply a tile repair material with a pneumatically controlled handheld applicator (note: this tile repair concept is no longer considered for use). Had it been used, the repair material would have been "smoothed" with special tools to minimize surface protrusions that could have led to transition. Furthermore, as the material was a cure-in-place ablator, the char layer formed during entry would not have been shape stable; swelling (protuberance) and outgassing (mass addition) into the boundary layer would have occurred during entry, so both effects on transition had to be considered in the experimental program, Fig.1. The heritage roughness criteria for the Shuttle program is not able to quantify the expected transition time associated with these specific types of localized perturbations to the nominally smooth surface. The experimental boundary layer transition wind tunnel program was designed to simulate the surface conditions associated with limited types of TPS damage/repair; that is, cavities from un-repaired tile damage, protuberances from RCC (nose or wing leading edge) or tile repairs, and localized out-gassing from tile damage sites repaired with the proposed ablating compound.

A promising Orbiter-specific transition correlation methodology was identified for protuberances ${ }^{10}$. In general, isolated protuberance induced transition has been extensively investigated experimentally and theoretically and is well documented in the open literature. References 11-20 provide a few of the relevant historical reports on the subject of roughness induced boundary layer transition at hypersonic speeds. While the Shuttle Orbiter flight history with early boundary layer transition ${ }^{21}$ and supplemental wind tunnel data form the basis for the protuberance height restriction, little is known about the influences of isolated cavities. Thus, experimentalists were tasked with the development of enhanced (protuberances) or new (cavities, ablation) wind tunnel databases from which to determine Shuttle boundary layer transition thresholds from TPS damage/repair. Relatively speaking, studies involving hypersonic transition induced from cavities or localized ablators are scarce in the open literature. Understanding the detailed physical dynamics of cavity flows or mass addition leading to transition was beyond the scope of the desired Orbiter engineering assessment capability. A review of the literature served to guide the initial framework of the Orbiter specific experimental program, and in particular the ablation screening studies. The following section briefly reviews the public-release literature for information relevant to hypersonic boundary later transition downstream of cavities and localized ablating surfaces (as opposed to transition on large acreage ablating heatshields).

\section{Cavities}

Some similarities in local flow features and physics within a Shuttle damage (cavity) site may be inferred from a larger body of work, namely, the supersonic weapons store problem. In an open weapons bay, the approaching boundary layer separates from the bay leading edge and may pass over or be entrained into the weapons store area (i.e., a large "cavity"), depending on the bay dimensions. Within this geometrically large cavity, flow separation, reattachment, recirculation, vorticity, unsteadiness, resonance and transition are all possible. One important conclusion to draw from this large body of literature [see Charwat $(22,23)$ and Nestler (24)] is that for supersonic conditions there are two stable flow regimes associated with flow over a rectangular 2-D cavity. For cavities of sufficient length-to-depth (L/D) ratio, the boundary layer flow approaching the cavity enters into the cavity and the shear layer reattaches to the floor. This type of cavity flow is classically referred to as a closed cavity. In contrast, if L/D is sufficiently small, the flow essentially skips over the cavity. This type of cavity flow is classically referred to as an open cavity. A grey area exists where the cavity flow oscillates between open and closed behavior. Naturally, a TPS damage site (cavity) on the Orbiter is at a far smaller geometric scale. Whether a cavity exhibits open or closed behavior depends largely on both the local flow conditions and the cavity dimensional characteristics. The Shuttle, as opposed to military aircraft, re-enters at far greater speeds 
$(M=25)$ and flies at relatively high angles of attack $(\alpha=40-\mathrm{deg})$ to manage heating rates and loads during entry. Despite hypersonic freestream Mach numbers, the Shuttle post shock Mach numbers are generally supersonic $(1<\mathrm{M}<4)$ with local boundary layer edge Mach numbers between 2-3 downstream of the rapid expansion about the nose and wing leading edge. Thus, much of the local flow phenomenon associated with the available supersonic literature is arguably relevant. From the Shuttle perspective, these flow phenomenon along with the location, size, and orientation of a cavity from impact damage will, at some point during entry, destabilize the boundary layer/shear layer resulting in premature transition downstream.

References 25-39 provide a few of the relevant historical reports on the subject of cavity induced boundary layer transition at hypersonic speeds. It is commonly believed that cavities which are long in the streamwise direction are much more important than cavities that are long spanwise and narrow streamwise $^{39}$. This would support the hypothesis that it is transition in the shear layer above the cavity that induces transition of the flow downstream of the cavity. It is reasonable to postulate that a larger shear layer length Reynolds number is more likely to lead to transition, other things being equal. A cavity, which is longer in the streamwise direction, is more likely to induce transition downstream. It also seems plausible that long streamwise cavities introduce streamwise vorticity into the flow, similar to 3-D roughness elements, and that this is a likely tripping mechanism. Several studies focused on 2-D cavity geometries. Ginoux ${ }^{26}$ examined transition aft of a 2-D rectangular cavity placed on a sharp 20-degree wedge. Shadowgraphs were used to determine that the $\mathrm{L} / \mathrm{D}=2.5$ cavity tested at $\mathrm{Re} / \mathrm{ft}=6 \times 10^{6} \mathrm{did}$ not induce transition. Ginoux ${ }^{25}$ also examined transition aft of an axisymmetric cavity on a 10-degree half sharp circular cone at Mach 5.3 (edge Mach number somewhat higher than Shuttle). Transition onset downstream of the $\mathrm{L} / \mathrm{D}=1.85$ and 2 cavities were measured at $\mathrm{Re} / \mathrm{ft}=4.94 \times 10^{6}$. Effective transition (immediately behind cavity) was not obtained.

A gap simulating the nosecap RCC/tile interface on a $4 \%$ scale Shuttle was tested by $\mathrm{Carver}^{28}$ in Arnold Engineering Development Center Tunnel B. Relative to transition onset location obtained on a smooth baseline Shuttle, no movement in onset location was observed in the presence of a 0.040 -in. long, 0.080 -in. deep annular gap $(\mathrm{L} / \mathrm{D}=0.5)$ at $\mathrm{Re} / \mathrm{ft}=2.0 \times 10^{6}$. No data was taken at higher or lower Reynolds numbers so there is no way to determine when transition onset began or what the effective Reynolds number may have been.

Cheatwood ${ }^{34}$ and Hollis ${ }^{36}$ presented measurements related to transition on blunt bodies with cavities, as part of studies carried out for the design of heatshields for planetary probes. In these two studies, the presence of penetrations (circular cavities) during entry were a design concern due to the possibility of localized heating augmentation at the downstream cavity wall from flow separation and subsequent reattachment within the cavity. The penetrations also served as a potential disturbance source that could induce boundary layer transition downstream of the cavity site. In both cases, the bodies were very blunt, so that the flow over the cavity is subsonic, possibly causing significant differences from the Shuttle case. These studies were included as correlations were developed that defined laminar-turbulent thresholds based upon dimensional characteristics of the cavity and local boundary layer properties at the cavity site.

\section{Localized Ablators}

Influences of ablation on boundary layer transition have been generally restricted to earth and planetary hypervelocity entries with vehicles having blunt heatshields; most of these applications involve massive ablation ${ }^{40}$ from the heatshield as opposed to the isolated case corresponding to a tile repair. Ablating antennae windows found in some high performance reentry vehicles may provide insight into the influence of an isolated ablator (possibly in the presence of a cavity), but much of this information would not be available in the public domain. Isolated blowing has also been studied from an aerodynamic control perspective, but the blowing rates (relative to that from an ablating material) are generally too large to apply to the tile repair issue.

Several studies have shown that gaseous injection into the boundary layer has a significant effect on transition (promoting or delaying) depending on the flow rate, distribution, and molecular weight of the gas. Berry et. al. ${ }^{41}$ demonstrated that mass injection from discrete orifices could successfully induce boundary layer transition consistent with that observed with the more conventional protuberance-based discrete roughness. Stalmach et. Al., ${ }^{37}$ used three gases (molecular weights 16 to 86 ) to determine distributed mass injection effects on transition on a sharp 12-degree half angle cone at Mach 7 and 12. 


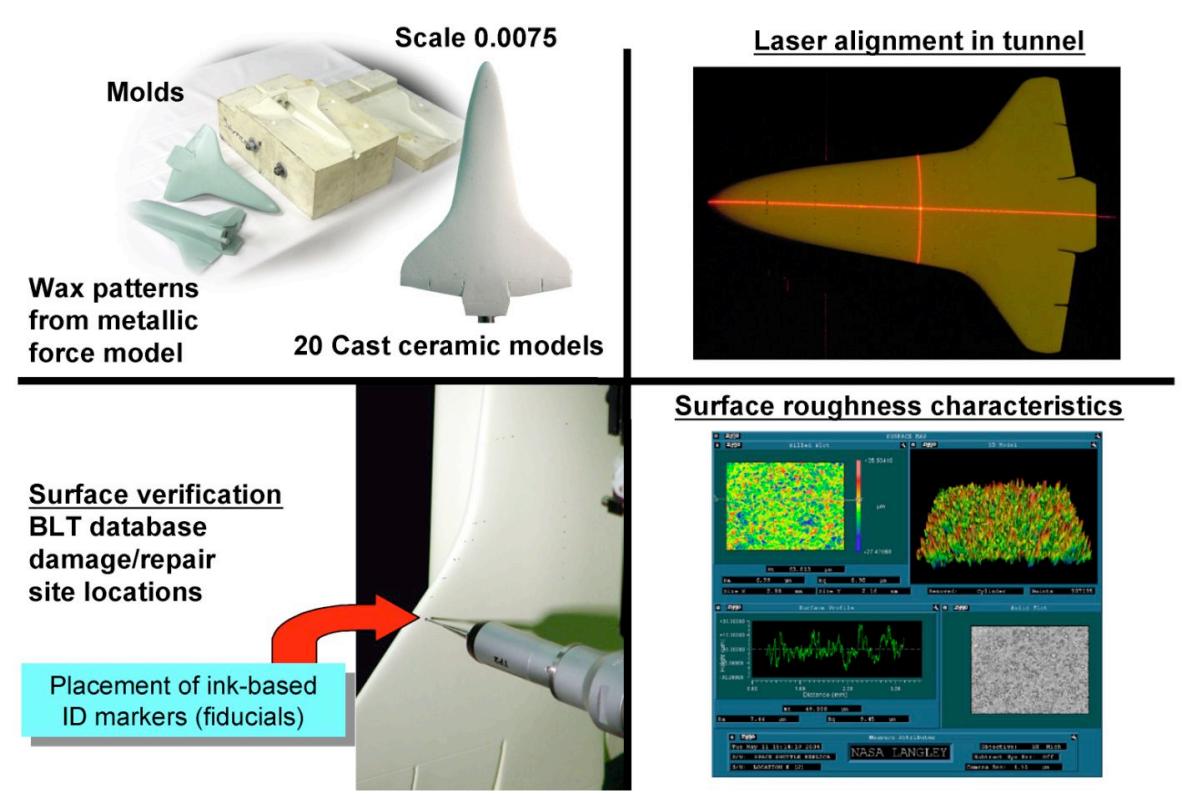

Fig. 2 Ceramic model fabrication and preparation

Stalmach concluded that the heavy molecular weight gases stabilized the boundary layer by increasing the density near the surface in a manner similar to the well-known wall cooling stabilizing effect. The measurements were obtained in a hot-shot tunnel and the flow quality was thus questionable. From a qualitative perspective, the movement of transition onset location as a function of the gas molecular weight is consistent with other studies.

Ginoux ${ }^{25}$ examined the effects of isolated mass injection on transition. Gases of various molecular weights were injected into the flow from an axisymmetric cavity located on a on a 10-degree half sharp circular cone at Mach 5.3. With no blowing, transition onset was located downstream of the $\mathrm{L} / \mathrm{D}=1.85$ and 2 cavities. Injection of air or light gases (helium or hydrogen) produced an upstream movement movement of the transition onset location with increasing blowing rates. Consistent with the conclusions of Stalmach ${ }^{37}$ (see above), heavy molecular weight gases (such as Freon) delayed transition onset to the point of completely re-laminarizing the flow - up to a critical blowing rate. Beyond a critical mass flow rate, transition onset was again detected near the cone base and moved progressively forward with increasing blowing. In the presence of blowing, high frequency $(\sim 50 \mathrm{kHz})$ pressure fluctuations within the cavity suggested the presence of a complex instability mechanism.

The preceding literature review produced useful parametric trends and suggested ways to correlate the data. Shuttle specific data was lacking and it was felt that new experimental results on the Orbiter were required for cavities and ablation over as wide a range of simulation parameters as possible $\left(\alpha, \mathrm{M}_{\infty}, \mathrm{Re}_{\infty}\right.$, $\mathrm{T}_{\mathrm{W}}$, etc.). For protuberances, additional data along the wing leading edge and for a larger range of angles of attack were required.

\section{Experimental Methods}

\section{Wind tunnel models}

The cast ceramic models used in the RTF cavity and protuberance transition studies were fabricated from a pre-existing mold created from a machined 0.075-scale stainless steel aerodynamic model, Fig. 2. Standard methods, materials and equipment developed at NASA Langley Research Center (LaRC) were used in fabricating the ceramic aeroheating test models $^{42}$ for the present experimental studies. The fabrication process includes forming a wax pattern in the shape of the test model, using a lost-wax investment casting process to transform the pattern into a ceramic model, sintering the ceramic model to give it strength, mounting supports, machining cavities, coating with phosphor, marking fiducials (spatial 
location reference points) and applying protuberances. An optical 3D surface profiler was used for capturing high-resolution cavity geometries and making surface roughness measurements. Both uncoated and phosphor coated ceramic models were evaluated. Surface roughness values of approximately 400 micro-inches (rms) were measured on a Shuttle model prepared for testing (200 micro-inches on an uncoated model) which is more than an order of magnitude smaller than the smallest protuberance height tested. ${ }^{42}$

The models used in support of the ablation screening study were fabricated using the stereolithography (SLA) rapid prototyping method. With this approach a CAD part file is used to build the model crosssection by cross-section by focusing a laser into a bath of a liquid polymer resin. The wind tunnel model was manufactured to the same Cad description used to create a common structured grid system used for CFD in support of the Columbia Accident Investigation and RTF. The SLA fabrication approach had the advantages of manufacturing speed along with the fact that the internal gas delivery plumbing in the models was an integral part of the resin buildup of the model. To raise the temperature limit that the resin models could be exposed to during a typical run (320-degree F), they were coated with spray carbon.

Over 50 ceramic and 5 resin SLA models were manufactured over the course of the testing campaigns. Fiducial markings were applied to the model surface using a coordinate measuring machine (CMM). Fig. 2 shows the probe configuration during application of a fiducial point. The reference marks on the model surface were used to align the model in the tunnel and to aid in the placement of protuberances and cavities on the model. All models were supported in the wind tunnel by a base-mounted 0.75 -in. cylindrical sting. Details specific to the manufacture of simulated damage/repair (protuberances, cavities, and outgassing) on the models will be described in the corresponding results section.

\section{$\underline{\text { Facilities }}$}

The data to be presented have been based on measurements obtained in the NASA LaRC Aerothermodynamics Laboratory (LAL), Fig. 3. This laboratory presently consists of three hypersonic wind tunnels. ${ }^{43}$ Collectively, they provide a wide range of Mach number simulation (6-18), unit Reynolds number (0.01-8 million/ft), and normal shock density ratio (5.3 to 12). This range of hypersonic simulation parameters is due, in part, to the use of two different test gases (air and tetraflouromethane
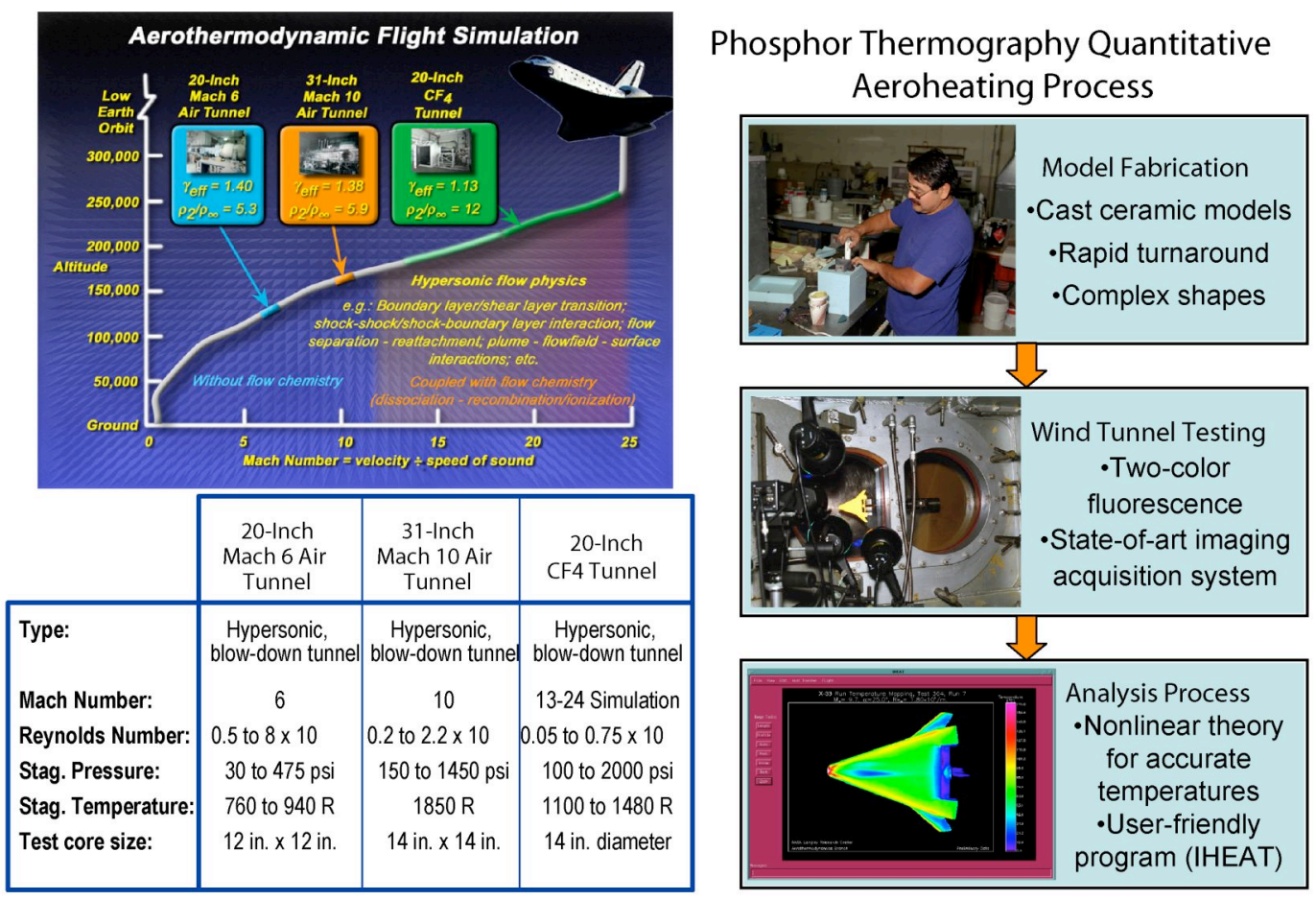

Fig. 3 Facilities and global heating technique used in RTF transition tests 
which is 3 times the molecular weight of air). The perfect gas flows are well characterized in terms of composition and uniformity. The LAL facilities offer run times from $20 \mathrm{sec}$ to 20 minutes (for the heattransfer/ transition tests, the model residence time in the flow is limited to a few seconds.) and are ideally suited for fast-paced aeroheating boundary layer transition studies.

The relative disturbance environment of all three hypersonic tunnels in the LAL is not known. Measurement of free-steam noise levels in the LaRC 20-Inch Mach 6 Air Tunnel using a hybrid constant current anemometer (CCA) have been recently obtained ${ }^{44}$ yielding mass flux and total temperature fluctuations of $0.83 \%$ and $0.17 \%$, respectively. When vehicle surface "roughness" is present, it is believed that the free stream noise contamination present in conventional tunnels has only a marginal, yet conservative effect, on the location of transition. Specifically, experimental studies ${ }^{45}$ have suggested that in general, facility noise has little effect for roughness heights large enough to be considered "effective" (for a protuberance, turbulence initiated immediately downstream of the roughness element site). It is recognized there may be an influence of wind tunnel noise on transition onset data derived from roughness that are less than "effective" (transition not at, but down stream of roughness site) ${ }^{46,47}$.

20-Inch Mach 6 Air Tunnel: Heated, dried, and filtered air is used as the test gas. Typical operating conditions for the tunnel are: stagnation pressures ranging from 30 to 500 psia; stagnation temperatures from $760 \mathrm{deg}$ to $1000 \mathrm{deg} \mathrm{R}$; and freestream unit Reynolds numbers from 0.5 to 8 million per ft. A twodimensional, contoured nozzle is used to provide nominal freestream Mach numbers from 5.8 to 6.1. The test section is 20.5 by 20 in; the nozzle throat is 0.399 by 20.5 in. A floor-mounted model injection system can insert models from a sheltered position to the tunnel centerline in less than $0.5 \mathrm{~s}$.

20-Inch Mach 6 CF4 Tunnel: Heated, dried, and filtered tetrafluoromethane $\left(\mathrm{CF}_{4}\right)$ is used as the test gas. Typical operating conditions for the tunnel are: stagnation pressures ranging from 85 to 2000 psia, stagnation temperatures up to $1300 \mathrm{R}$, and freestream unit Reynolds numbers from 0.01 to 0.3 million per $\mathrm{ft}$. A contoured axisymmetric nozzle is used to provide a nominal freestream Mach numbers from 5.9 to 6.01. The nozzle exit diameter is 20 in with the flow exhausting into an open jet test section; the nozzle throat diameter is 0.466 in. A floor-mounted model injection system can inject models from a sheltered position to the tunnel centerline in less than $0.5 \mathrm{~s}$. In conjunction with the Mach 6 air tunnel, this tunnel provides the capability to test at the same free-stream Mach and Reynolds numbers, but at two values of density ratio (approximately 5 in air and 12 in $\mathrm{CF}_{4}$ ). This density ratio of 12 for $\mathrm{CF}_{4}$ is relatively close to the values of 15-18 encountered near peak heating during entry of the Orbiter. Thus, generating large values of density ratio simulates many of the effects on aerodynamics and aeroheating associated with a high temperature gas.

31-Inch Mach 10 Air Tunnel: Heated, dried, and filtered air is used as the test gas. Typical operating conditions for the tunnel are: stagnation pressures ranging from 150 to 1350 psia; stagnation temperatures from $1750 \mathrm{deg}$ to $1850 \mathrm{deg} \mathrm{R}$; and freestream unit Reynolds numbers from 0.25 to 2 million per ft. A three-dimensional, contoured nozzle is used to provide nominal freestream Mach number of 10 . The test section is 31 by $31 \mathrm{in}$; the nozzle throat is 1.07 by 1.07 in. A side-mounted model injection system can insert models from a sheltered position to the tunnel centerline in less than $0.5 \mathrm{~s}$.

\section{Test Technique}

Phosphor Thermography: Advances in image processing technology have made digital optical measurement techniques practical for wind tunnel applications. One such optical acquisition method is two-color relative-intensity phosphor thermography ${ }^{48,49,50}$ which has been utilized in several aeroheating tests conducted in the hypersonic wind tunnels of NASA LaRC ${ }^{10,51,52}$. The process surrounding this global technique is shown in Fig. 3. All Shuttle surface heating data used to infer transition from simulated damage/repair was obtained from phosphor thermography. With this technique, ceramic wind-tunnel models are fabricated and coated with phosphors that fluoresce in the visible spectrum when illuminated with ultraviolet light. The visible fluorescence from the model surface is emitted with a spectral distribution of intensity that is temperature dependent. By acquiring fluorescence intensity images with a two-color video camera of an illuminated phosphor model exposed to flow in a wind tunnel, surface temperature mappings can be calculated on the portions of the model that are in the field of view of the camera. A temperature calibration of the system conducted prior to the study provides tables used to convert the ratio of green and red intensity images to global temperature mappings. The two-color 
approach removes the fluorescence dependency on the incident illumination levels. With temperature images acquired at different times during a wind-tunnel run, global heat-transfer images are computed assuming one-dimensional semi-infinite heat conduction. The primary advantage of the phosphor technique is the global resolution of the quantitative heat-transfer data. Such data can be used to identify the heating footprint of complex, three-dimensional flow phenomena (e.g., transition fronts and turbulent spreading angles) that are extremely difficult to resolve by discrete measurement techniques.

Flow Visualization: When appropriate, flow visualization in the form of schlieren and surface oilflow was used to complement the surface heating/transition tests. The LaRC 20-Inch Mach 6 Air and $\mathrm{CF}_{4}$ Tunnels are equipped with a pulsed white-light, Z-pattern, single-pass schlieren system with a field of view encompassing the entire test core. Images were recorded on a high-resolution digital camera and enhanced with commercial software.

Surface streamline patterns were obtained using the oil-flow technique. Backup ceramic models were spray-painted black to enhance contrast with the phosphor-impregnated oils used to trace streamline movement. A thin coat of clear silicon oil with phosphor particles in suspense was applied onto the surface. After the model surface was prepared, the model was injected into the air stream. The phosphor was illuminated with UV light and the development of the surface streamlines was recorded with a conventional video camera. The model was retracted immediately following flow establishment and formation of streamline patterns, and post-run digital photographs were taken.

\section{Computational Method}

\section{Numerical Database and Boundary Layer Properties Interpolation Tool}

To support the BLT Task, computational solutions at both wind tunnel and flight conditions were required. The wind tunnel solutions were used to generate the BLT correlation, while the flight solutions provide the means with which to apply the ground-based correlation at flight conditions. With the large number of solutions required to cover a typical Shuttle trajectory, a new boundary layer properties (BLPROP) interpolation tool was generated to minimize the number of flight solutions and to automate the process of obtaining the necessary boundary layer data. The numerical database, were first computed with LAURA $^{53}$ to provide the inviscid flow field and then coupled with $\mathrm{LATCH}^{54}$ to determine the boundary layer properties. The BLP database tool then interpolates both spatially within the solution grid to obtain the local properties at each damage or repair site of interest, then interpolates temporally within the solution database to provide the boundary layer properties along the trajectory. Greene ${ }^{7}$ provides a more detailed description of the BLPROP tool and the solutions used to generate the boundary layer transition results for RTF.

\section{$\underline{\text { Results }}$}

\section{Protuberances}

Approximately 550 wind tunnel runs were performed on ceramic Orbiter models to determine the effect of an isolated protuberance on hypersonic boundary layer transition of the windward surface of the Shuttle Orbiter. Previous protuberance testing on the Shuttle at LaRC had resulted in a large experience base regarding trip design ${ }^{10,11}$. The isolated roughness elements that were utilized during the RTF BLT test campaign have evolved and been perfected over the last decade. In the manufacturing process, adhesively backed high temperature Teflon tape is cut with a laser to the desired planform shape. Height parametrics are controlled by the individual tape thickness. In previous studies, each protuberance was fabricated to simulate a single tile raised above the surrounding surface (analogous to a pizza box on a table). All RTF BLT testing that provided data to form a correlation was obtained on this heritage shape. Over the last two years, various TPS repair concepts have been suggested that do not fall into the pizza box context. A wing leading edge plug repair concept is one such example (analogous to a hockey puck on ice). To address such differences in shape, a limited number of tests were performed with roughness elements manufactured by programming the laser to cut the desired shape. The present paper does not document these screening tests. The limited protuberance shape testing has indicated that the swept sharp edges associated with the raised tile concept are more effective at initiating boundary layer transition - resulting in a more conservative correlation. The focus of the new protuberance based BLT testing was to enhance the existing 


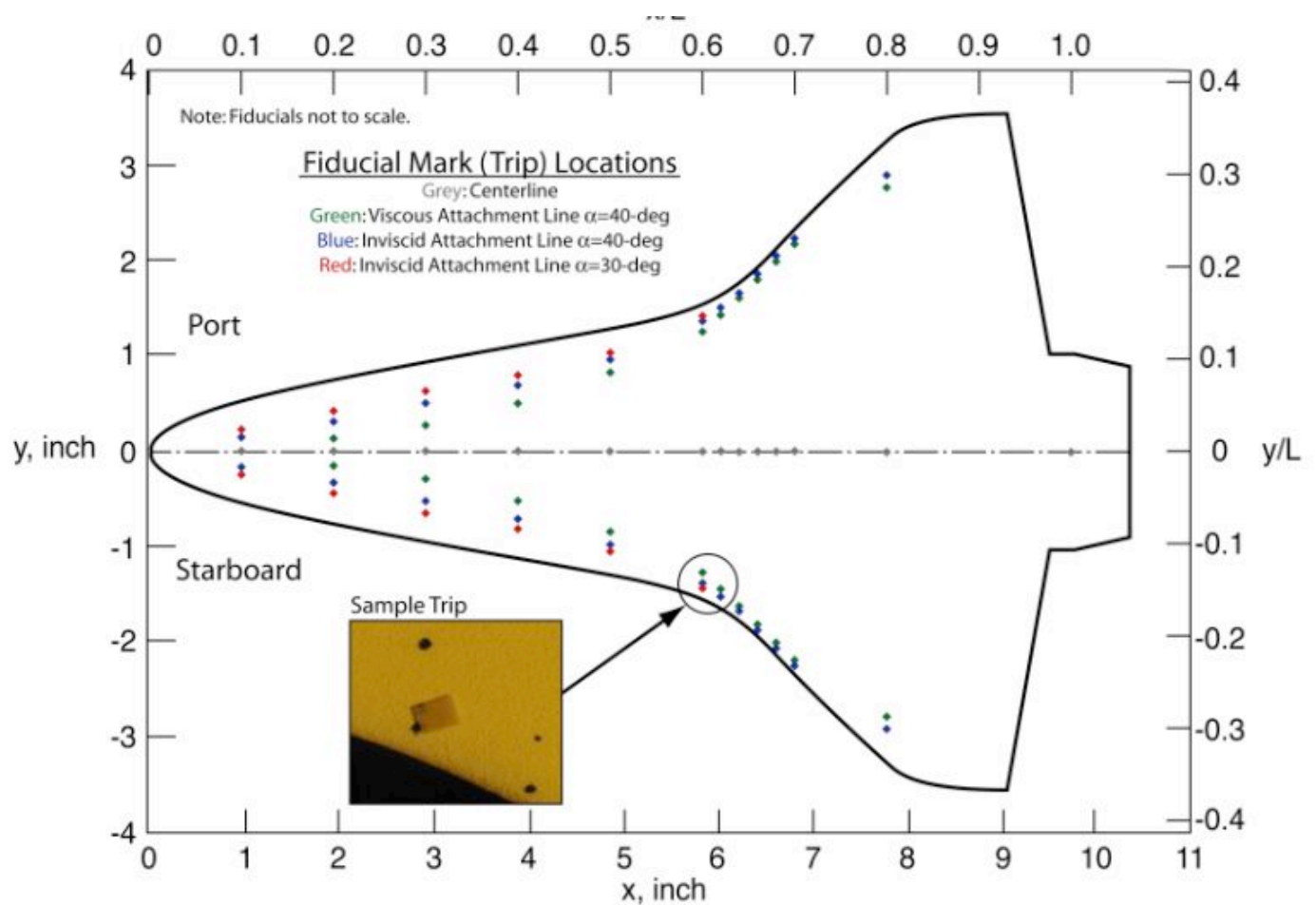

Fig. 4 Sketch of 0.0075 scale Orbiter showing fiducial mark locations and photograph of trip

database by extending its range of applicability to off-centerline locations. Of particular interest was the attachment line where others have suggested an increased sensitivity to roughness ${ }^{55}$. Previous testing at LaRC on another moderately blunt configuration (X-33) had not shown this sensitivity ${ }^{56}$ but it had never been demonstrated on the Shuttle thus, the off-centerline attachment line location parametric was of prime importance. Placement of trips along the wing attachment line (where the local boundary thickness was small) also had the added benefit of extending the range of applicability of the correlation to higher protuberance height-to-boundary layer thickness ratio $(\mathrm{k} / \mathrm{\delta})$ values.

The boundary layer trips used in the present tests were 0.050 -in $\times 0.050$-in with nominal heights of $0.0035,0.0045,0.0065$, and 0.0115 -in. The fiducial marks on the surface of the models facilitated the precise placement of the trips on the surface. Fig. 4 shows a sketch of the Orbiter windward surface indicating the fiducial mark locations and details of the trip shape. To enhance run productivity and provide a sense of repeatability, trips of identical height were placed on the model centerline and the port and starboard attachment lines. Oil flow visualization, Fig. 5, was used to determine the attachment line position (red-black interface via image post processing) and correlate its location with viscous predictions (see Fig. 4). However, subsequent heating tests (not shown) suggested the use of the attachment line

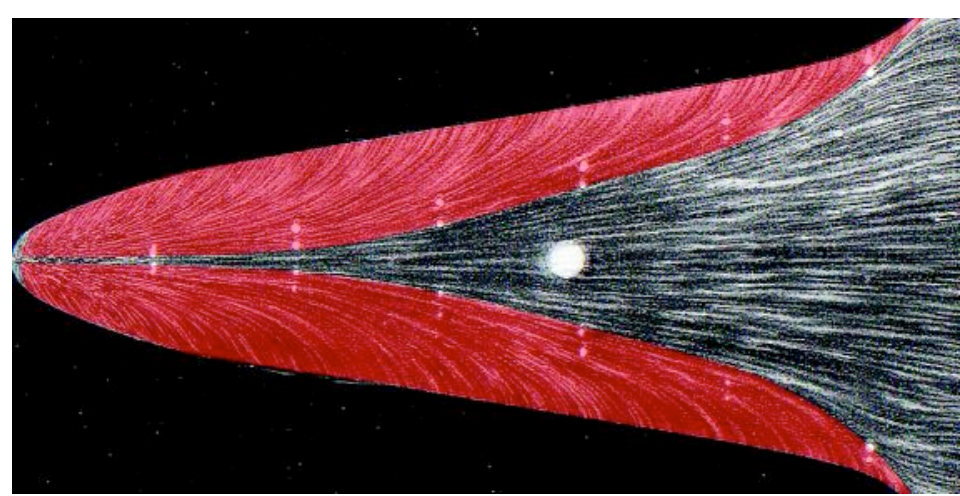

Fig. 5 Attachment line as determined by surface oil flow defined by inviscid CFD for protuberance trip placement. That is, measured surface disturbances from protuberances propagated toward the wing leading edge from the inviscidly computed attachment line as opposed to the attachment line inferred from viscous numerical solutions. This observation is reconciled by the fact that disturbances from the large protuberances $(\mathrm{k} / \mathrm{d} \sim 0.5)$ are most amplified at the top of the trip 


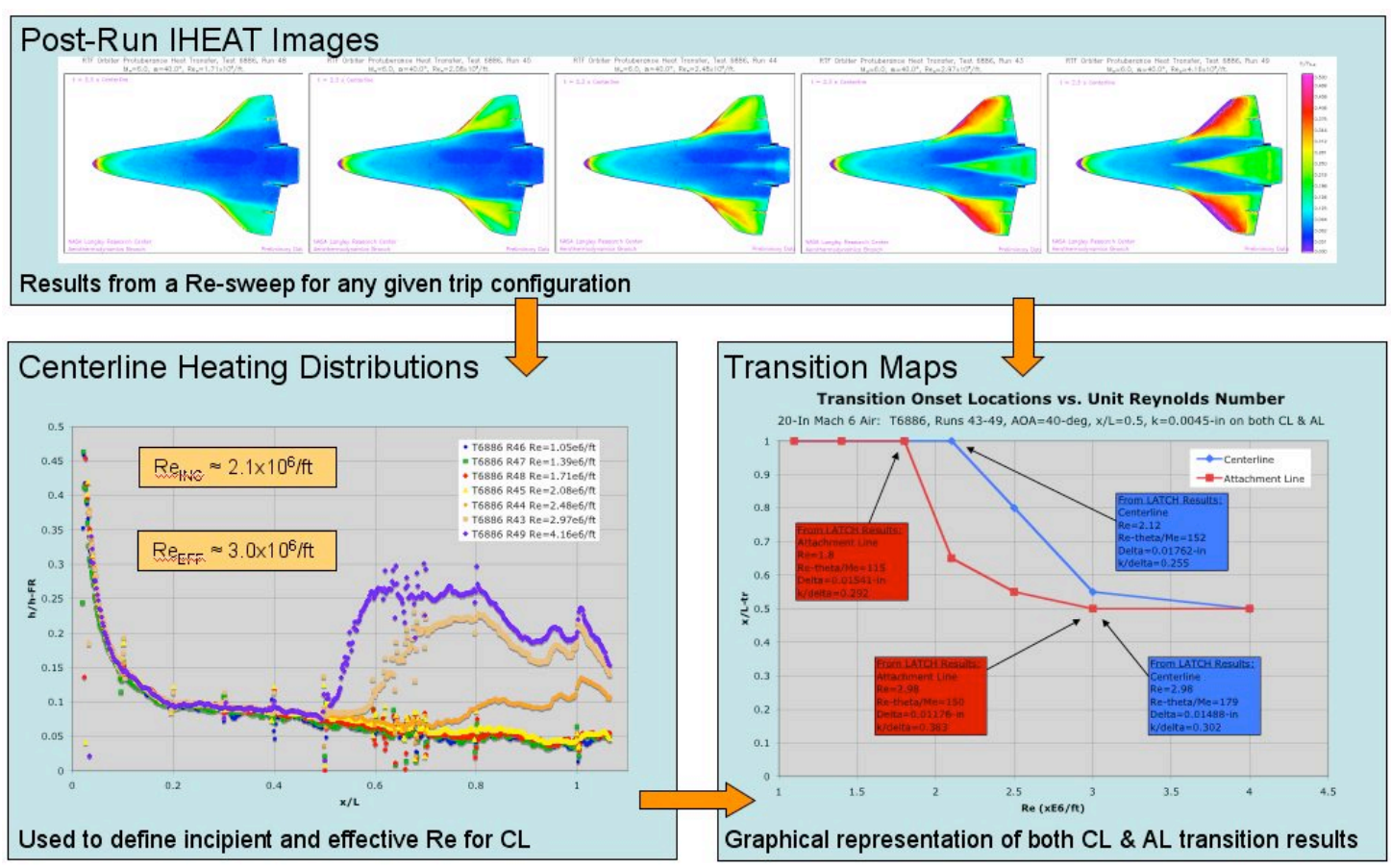

Fig. 6 Process for determination of protuberance boundary layer transition onset

near the critical layer and or supersonic boundary edge ${ }^{57}$ (inviscid solution) as opposed to near the wall (viscous solution). Test parametrics included angle of attack of 30 and 40 degs, sideslip angle of 0 deg, freestream unit Reynolds numbers from $0.02 \times 10^{6}$ to $7.3 \times 10^{6}$, edge-to-wall temperature ratio from 0.4 to 0.8 , and normal shock density ratios ranging from 5.3 to 12 . The entire heating data set from all three hypersonic wind tunnels has been documented in Ref. [58].

Global heat transfer images using phosphor thermography of the Orbiter windward surface and the corresponding centerline heating distributions were used to infer the state of the boundary layer (laminar, transitional, or turbulent). The correlation methodology adopted by the technical BLT team required the location of transition onset behind a protuberance to be identified and the progressive movement towards the roughness site to be determined. The process of how this was accomplished is represented in Fig. 6. Global heating measurements are obtained over a range of Reynolds numbers. The protuberances placed at $\mathrm{x} / \mathrm{L}=0.5$ on the centerline and port/starboard attachment lines create disturbances that are revealed as increases in local heating (based upon the images alone, transition is first observed on the wings). Based upon the images, transition onset locations are then inferred from the corresponding centerline normalized heating distributions (heat transfer distributions along the attachment line could not be readily extracted from the global images and thus the onset locations were identified more subjectively from global images). Onset was defined as the departure of the heating distribution from the baseline laminar level. The nondimensional onset locations $(\mathrm{x} / \mathrm{L})_{\mathrm{tr}}$ were subsequently plotted as a function of unit Reynolds number to form a transition map. There exists a corresponding transition map for each of the roughness locations (axial stations) tested at 30 and 40-deg angle-of-attack in each of the three hypersonic tunnels. This approach has been successfully used for previous Shuttle transition testing at LaRC and is similar to analysis reported in Ref. [11]. Due to the limited granularity of the Reynolds number test points, the transition maps form the basis of a method to infer the actual incipient (first departure from baseline laminar heating) and effective (transition onset to protuberance site) onset Reynolds numbers associated with each individual protuberance and angle-of-attack. The resulting transition onset map for a typical protuberance is shown in Fig. 6. A value of $(x / L)_{\operatorname{tr}}$ of 1 signifies that the protuberance had no effect and transition onset was not observed on the Shuttle. An $(\mathrm{x} / \mathrm{L})_{\mathrm{tr}}$ value corresponding to the axial location of the protuberance signifies a fully effective trip. Any value in between represents a critical case. Previous experimental work ${ }^{11}$ has demonstrated that the curve representing the movement as a function of Reynolds number is fairly smooth and shows a distinctive sharp bend as the effective value is approached 


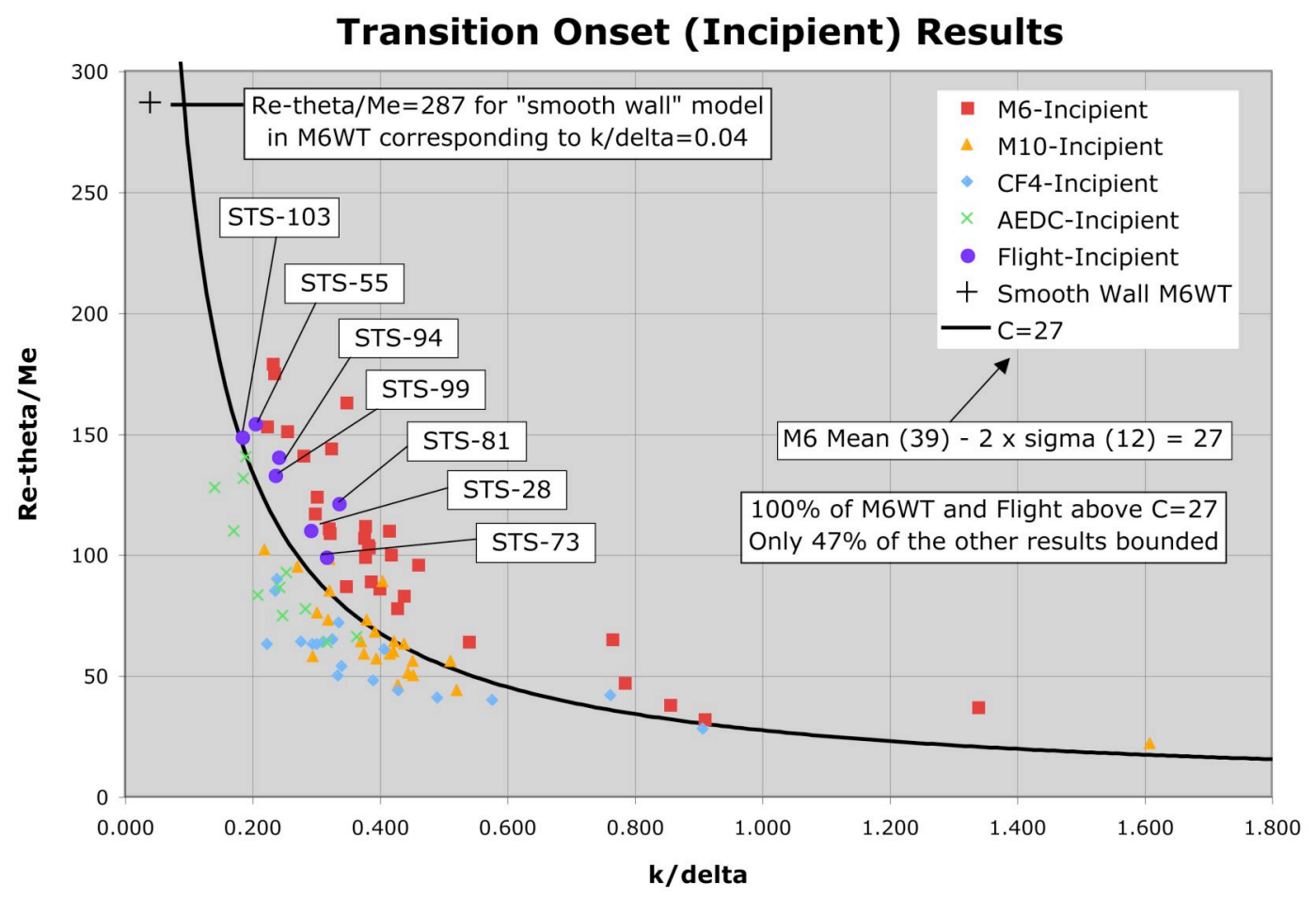

Fig. 7 Protuberance correlations used for STS-114

asymptotically. As shown in Fig. 6, the Reynolds number test point increments were too coarse to use a straight-line approximation to infer the effective values. When required, a smooth curve fairing of the transition map data was used to better define the incipient and effective transition point Reynolds numbers. When correlated against local properties at the protuberance site, transition onset along the attachment line was consistent with centerline observations.

As discussed by Berry ${ }^{6}$, the initial position going into this activity was to utilize a simple correlation methodology $\left(\operatorname{Re}_{\theta} / \mathrm{M}_{\mathrm{e}}\right)$ employing a simple engineering-based method to compute local conditions at the roughness site. In the case of a protuberance, the disturbance parameter $(\mathrm{k} / \delta)$ was to be based upon the trip height $(\mathrm{k})$. As noted by Berry, the simplicity of this approach is that if the data falls along the straight line represented by $\left(\operatorname{Re}_{\theta} / \mathrm{M}_{\mathrm{e}}\right)(\mathrm{k} / \mathrm{\delta})=\mathrm{C}$, where $\mathrm{C}$ is a constant, then the disturbance height, $\mathrm{k}$ can be directly linked to the transition parameter. See Ref. 54 for a discussion of how the boundary layer thickness and corresponding local edge properties were computed with the two layer method LATCH. As the new centerline and off-centerline data became available from all three facilities, this dependency was corroborated. Unfortunately, the curve coefficient, C, was not universally consistent between the facilities. A modified approach using a temperature ratio correction along with the momentum thickness (instead of the boundary layer thickness) as the disturbance parameter, was found to more effectively collapse all three datasets (see Ref. 6). However, when this modified correlation approach was applied to the existing flight calibration cases the results were again inconsistent. In the end, it was determined that the original approach using the curve coefficient associated with the 20-In Mach air data provided the best comparisons relative to the flight calibration cases. These findings were presented to a Peer Panel in hopes of reaching group consensus as to the best approach to use for moving forward with the first RTF mission.

Based on the recommendations of the technical peer panel and concurrence with the Orbiter Configuration Control Board (OCCB), the protuberance BLT correlation used to support STS-114 was based on wind tunnel results along with a limited number of flight calibration cases ${ }^{6,8}$. A curve coefficient of 27 was selected to conservatively capture, with $95 \%$ confidence, transition onset (incipient) for all the Mach 6 wind tunnel and flight data, shown in Fig 7. [Post STS-114, higher Mach number testing has been performed in a reflected shock tunnel (CUBRC) with protuberances on a scaled Shuttle model. Additional testing and analysis has been planned at LaRC and CUBRC to assess the effects protuberance shape (more gap filler-like) and higher Mach number]. As this information has not been OCCB certified, it has not been presented. 


\section{Cavities}

Approximately 400 wind tunnel runs were performed on 14 ceramic Orbiter models to determine the effect of an isolated cavity on hypersonic boundary layer transition of the windward surface of the Shuttle Orbiter. Actual tile damage geometry from flight experience or from laboratory impact testing is very threedimensional (for the purposes of this experimental work, tile damage is assumed to be non-breachingflow path to the Orbiter interior does not exist). Because an infinite number of cavity geometries are possible in-flight (and they are difficult to manufacture at model scale) it was decided to perform testing on simplified cavity geometries more representative of a missing tile or a tile array

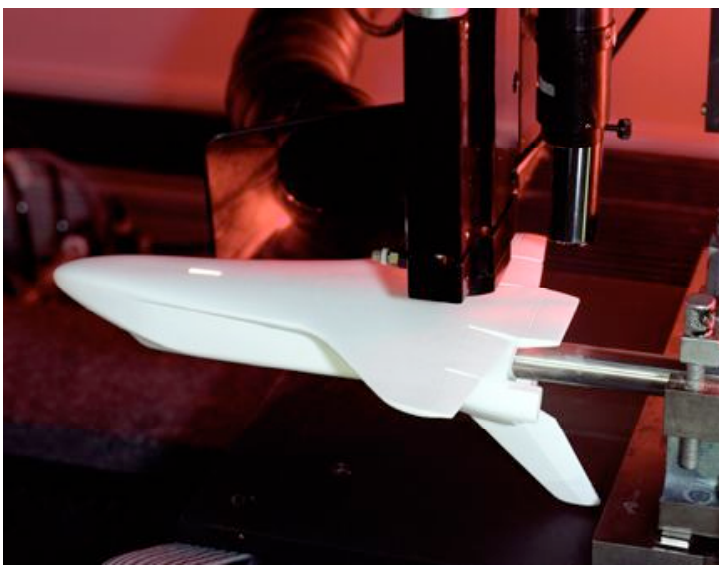

Fig. 8 Laser ablation setup (i.e., rectangular shoebox) rather than an actual impact site. This approach facilitated a systematic characterization of the influence of cavity dimensions (length, width, and depth) on transition.

Conventional machining (milling) could not accurately and repeatedly capture the desired cavity dimensions. A high energy $\mathrm{CO}_{2}$ laser system was used to remove (etch) material and form cavities in the ceramic test models, Figs. 8 and 9. Programming the laser for the desired cavity size and geometry controlled cavity dimensions. The number of passes made by the laser controlled the cavity depth. Cavity depth was measured with the laser system's vertical height sensor and verified with a depth micrometer. The $x-y$ dimensions of each cavity were verified using the video camera alignment system. When possible, cavity dimensions were verified using a coordinate measuring machine.

The cavity design strategy is illustrated in Fig. 10. The cavity was positioned at a fixed location $(\mathrm{x} / \mathrm{L}=$ 0.3 ) along the model centerline in a region of near zero pressure gradient (the relatively flat surface in this location simplified the setup of the model in the laser ablation apparatus). To determine the nominal cavity depth (D) at wind tunnel model scale the local boundary layer thickness $(\delta)$ was computed at this location for $\alpha=40-\mathrm{deg}$, Mach 6 , and $\mathrm{Re} / \mathrm{ft}=4 \times 10^{6}$. In flight, with $\mathrm{D}$ equal to a full tile thickness, the maximum value of $\mathrm{D} / \delta$ anywhere on the Shuttle windward surface is approximately 2.5 . Thus, at wind tunnel conditions, with a local boundary layer thickness of 0.012 -in at $\mathrm{x} / \mathrm{L}=0.3$, a nominal cavity depth of 0.030 in. was required to satisfy the ratio $\mathrm{D} / \delta=2.5$. Cavity length-to-depth ratio was then systematically varied from 2.5 to 17.7 in anticipation of identifying "open" and "closed" cavity flow behavior as suggested by Charwat ${ }^{23}$. At the time of test inception, this same classification was also used by the local cavity heating team $^{5}$. For the range of conditions tested, cavity depth-to local boundary layer thickness $(D / \delta)$ varied from 0.5 to 4.8. Cavity length-to-width (L/W) ratio ranged from of 1 to 8.5. Test parametrics included angle of attack of 30 and $40 \mathrm{degs}$, sideslip angle of $0 \mathrm{deg}$, freestream unit Reynolds numbers from $0.02 \times 10^{6}$ to $7.3 \times 10^{6}$, edge-to-wall temperature ratio from 0.4 to 0.8 , and normal shock density ratios ranging from 5.3 to 12. The entire data set from all three hypersonic wind tunnels has been documented in Ref. [59].

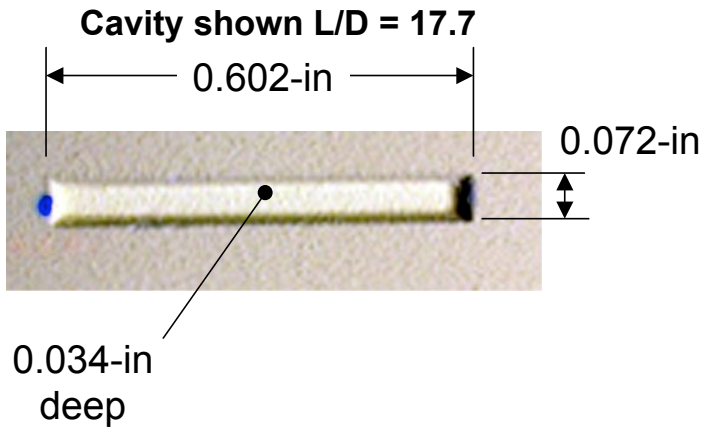

Fig. 9 Typical laser ablated cavity
Global heat transfer images using phosphor thermography of the Orbiter windward surface and the corresponding centerline heating distributions were used to infer the state of the boundary layer (laminar, transitional, or turbulent). In Mach 6 air, $\alpha=40-$ deg, a zone of disturbed flow located downstream of an open cavity $(\mathrm{L} / \mathrm{D}=2.47)$ develops with increasing Reynolds number as observed in Fig. 11. The precise location of the transition onset location is somewhat difficult to determine from the images alone. The global heating patterns are however, very useful in the 


\section{Cavity Geometry to Develop Database For BLT Correlations}

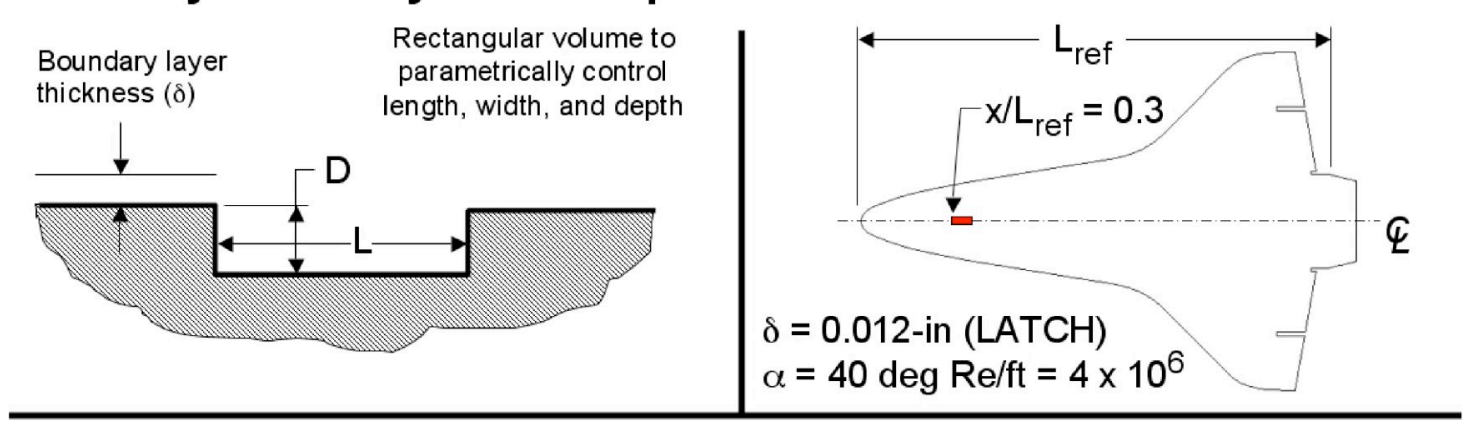

Assumption : max tile thickness / local bl thickness $(D / \delta)<2.5 @$ Orbiter entry conditions (source: Everhart LaRC). Relevant cavity depth at model scale determined by $\delta$ from WT condition above and setting $D / \delta=2.5(D=0.030$ - in)

Flow classifications derived from $\mathrm{M} \sim 3$ turbulent database, $\mathrm{D} / \delta \sim 0.4$ (Charwat, 1961)

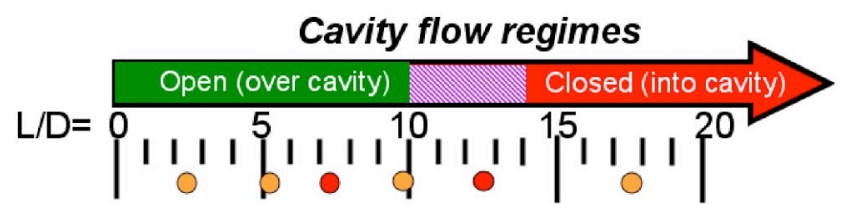

- Experimental database based upon damage geometry more representative of a missing tile array (i.e., rectangular shoebox) than an actual impact site

- Cavity geometry length-to-depth 2.5 to 17.7 ; length-to-width 1 to 8.5

- Damage depth-to-local boundary layer thickness 0.5 to 4.8

\section{Fig. 10 Cavity BLT test plan}

sense that the local spreading of the disturbed boundary layer is readily discernable. Transition was first observed on the wings due to a bow/wing shock-shock interaction. Transition onset from the cavity on the aft windward centerline is actually observed at $\mathrm{Re}=3.4 \times 10^{6}$. A progressive increase in Reynolds number to $\operatorname{Re}=5.4 \times 10^{6}$ resulted in fully turbulent flow immediately downstream of the cavity aft face. Inspection of digitally zoomed images of the cavity floor indicated that the flow did not enter the cavity as the boundary layer separated from the cavity leading edge. No elevated cavity floor heating was observed - a strong indication the cavity was indeed open as expected. Note the sensitivity of the turbulent spreading angle to Reynolds number.

A longer cavity $(\mathrm{L} / \mathrm{D}=17.7)$ shown in Fig. 12, exhibited closed cavity behavior. That is, based upon the elevated cavity floor heating, the shear layer has apparently entered into the cavity producing a highly 3dimensional flow. In terms of boundary layer transition downstream of the cavity, the closed $\mathrm{L} / \mathrm{D}=17.7$ is more effective (transition to turbulence at the cavity site) at lower Reynolds number values than the short cavity. This is not surprising since (1) the shear layer length Reynolds number would be larger for the longer cavity, and (2) the separated/reattaching flow within the cavity would produce 3dimensional flow structures promoting transition. One may infer from the close up heating image in Fig. 12, that the flow within the longer cavity appears to spread laterally and "spill"

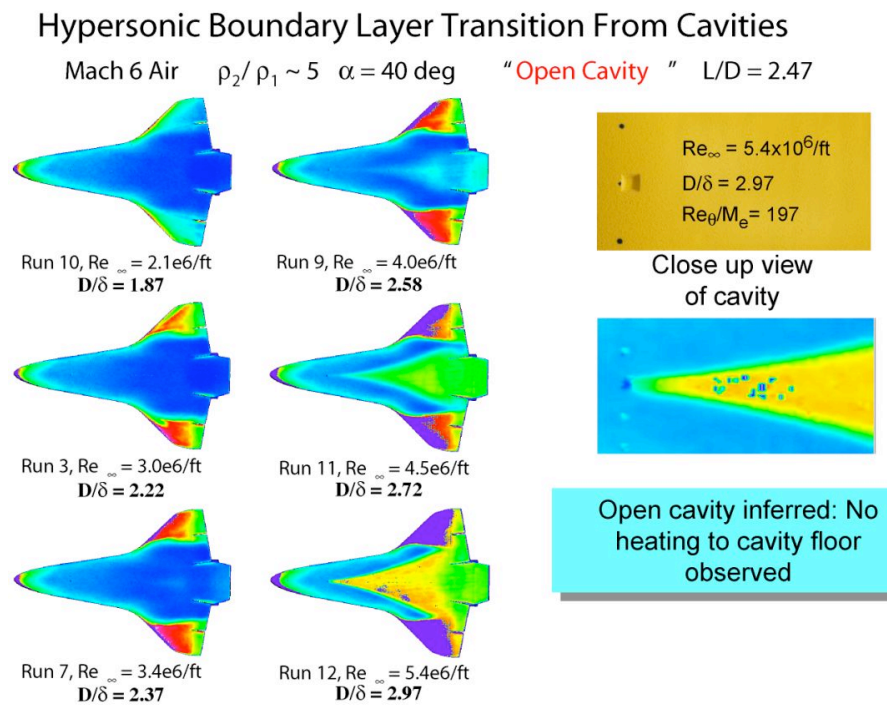

Fig. 11 Progression of transition - open cavity 
out of the simulated damage site. It is plausible that interaction of this vortical outflow with the cavity wake will more quickly destabilize the boundary layer that redevelops downstream.

The long cavities (L/D 20) that exhibit closed behavior, while interesting from a fluid dynamic perspective, are of less concern from a Shuttle damage assessment perspective. Historically, a very small percentage of actual flight tile impact damage fall into this category. Elimination of large debris sources should make damage of this nature even more unlikely. The present experimental long cavity data bounded the problem, provided insight into the complexity of the fluid flow, and when supplemented

Hypersonic Boundary Layer Transition From Cavities

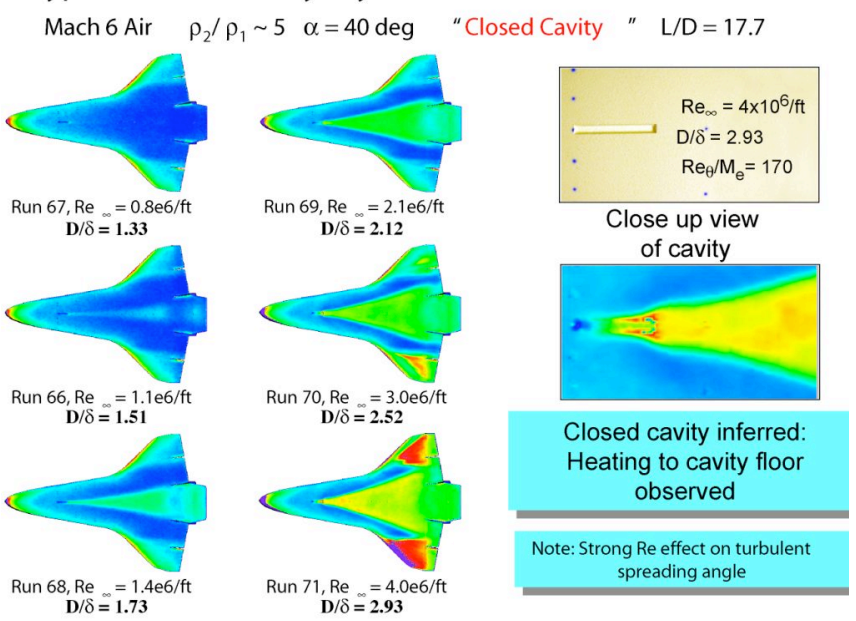

Fig. 12 Progression of transition - closed cavity with the shorter cavity data alluded to future challenges in correlating boundary layer transition to cavity dimensions. For example, Fig. 13 summarizes the effects of Reynolds number on local cavity heating. The heating distributions and the local images in the vicinity of the cavity were obtained by digitally zooming in from the full global image shown in Fig. 12. This long cavity $(\mathrm{L} / \mathrm{D}=17.7)$ actually exhibited both open and closed cavity behavior. Based upon the low heating measurements along the cavity floor at $\mathrm{Re}=$ $1.1 \times 10^{6}$ it is postulated that the shear layer passed over the cavity, indicative of an open cavity. The heating patterns observed downstream of the cavity (see corresponding global image, Fig. 12) suggested a disturbed wake flow for several cavity lengths before actual transition onset. From the global image in Fig. 12, it was observed that a small increase in Reynolds number to $1.4 \times 10^{6}$ appeared to move the location of transition onset to the cavity site. In contrast, the corresponding cavity floor heating levels (Fig. 13) continued to exhibit open cavity behavior suggesting the shear layer passing over the cavity was still

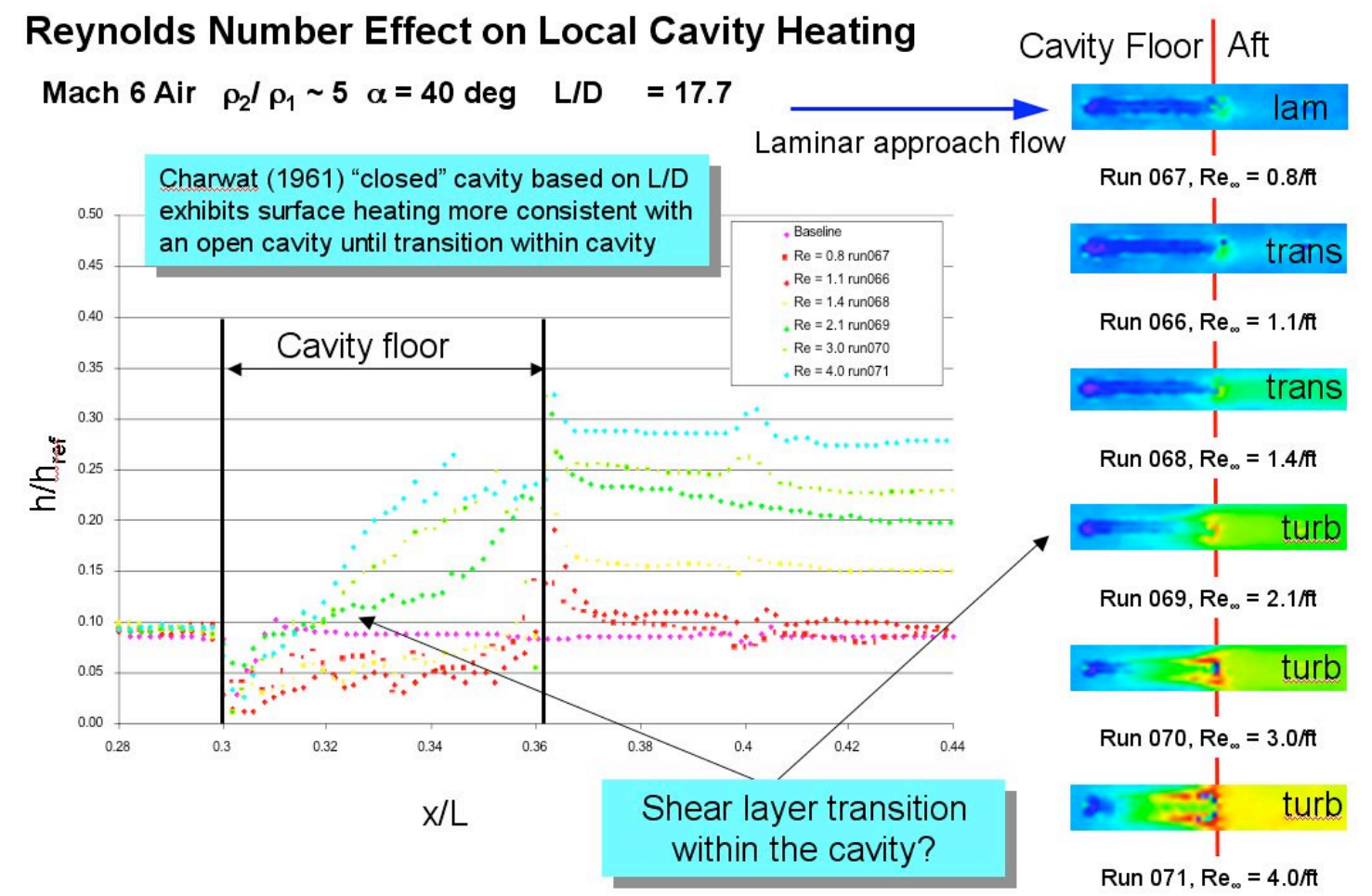

Fig. 13 Local cavity floor heating 
Test 6687 Mach 6 air; $\alpha=30$ deg; length $=0.074$-in, width $=0.071$-in, depth $=0.030$-in, L/D $=2.47$

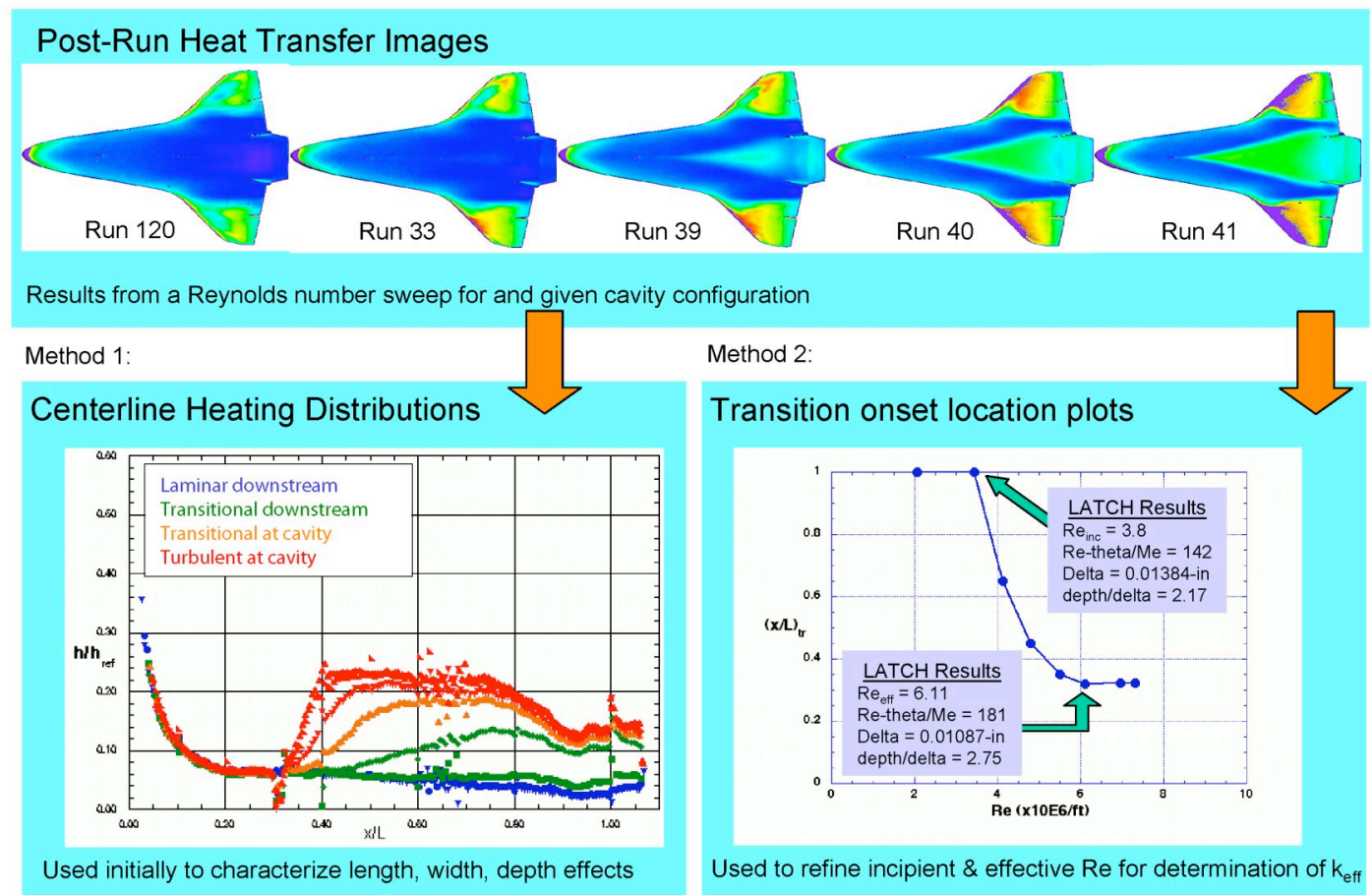

Fig. 14 Process for determination of cavity boundary layer transition onset

laminar. An increase of Reynolds number to $\mathrm{Re}=2.1 \times 10^{6}$ produced an abrupt increase in cavity floor heating levels indicative of the shear layer entering into the cavity and impinging on the cavity floor (i.e., a closed cavity). Naturally, the boundary layer immediately downstream of the cavity was turbulent. While the L/D ratio is an important parameter to classify open/closed cavity behavior and boundary layer transition, local properties must also be considered. Note that as Reynolds number is increased the local boundary layer thickness $(\delta)$ decreases; hence, the depth to the local boundary layer thickness ratio $(D / \delta)$ increases by a factor of approximately 2 over the Reynolds number range shown in Fig. 12.

Prior to testing, it was hoped that a correlation methodology based upon some unknown combination of cavity length, width, and depth could be developed. As initial cavity BLT test results were made available, it appeared that transition thresholds could be determined based exclusively on $\mathrm{L} / \mathrm{D}$ and $\mathrm{D} / \delta$. Unfortunately these simplistic approaches would not allow for the prediction of BLT time in the absence of damage depth (photographs from the International Space Station would only indicate cavity location, length, and width). Depth information would only be provided if laser scans were obtained with the robotic arm. Thus, near the end of the test campaign, a new correlation for transition was formulated based

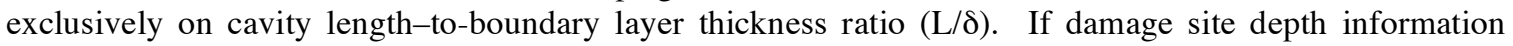
were obtained on orbit, transition onset times would be re-evaluated with cavity depth-to-boundary layer thickness ratio (D/8). Regarding tool certification prior to STS-114 launch, the BLT technical peer panel advocated separate correlations based upon cavity depth and length.

The correlation methodology ${ }^{6}$ adopted by the technical BLT team required the location of transition onset behind a cavity to be identified and the progressive movement towards the cavity site to be determined. The process of how this was accomplished is represented in Fig. 14. Similar to the protuberance methodology previously discussed, global heating measurements are obtained over a range of Reynolds numbers. Transition onset locations are then inferred from the corresponding centerline normalized heating distributions. Onset was defined as the departure of the heating distribution from the baseline laminar level. The non-dimensional onset locations $(\mathrm{x} / \mathrm{L})_{\mathrm{tr}}$ were subsequently plotted as a function of unit Reynolds number to form a transition map. There exists a corresponding transition map for each of the 14 cavity configurations tested at 30 and 40-deg angle-of-attack in each of the three hypersonic tunnels. Due to the limited granularity of the Reynolds number test points, the transition maps form the basis of a 

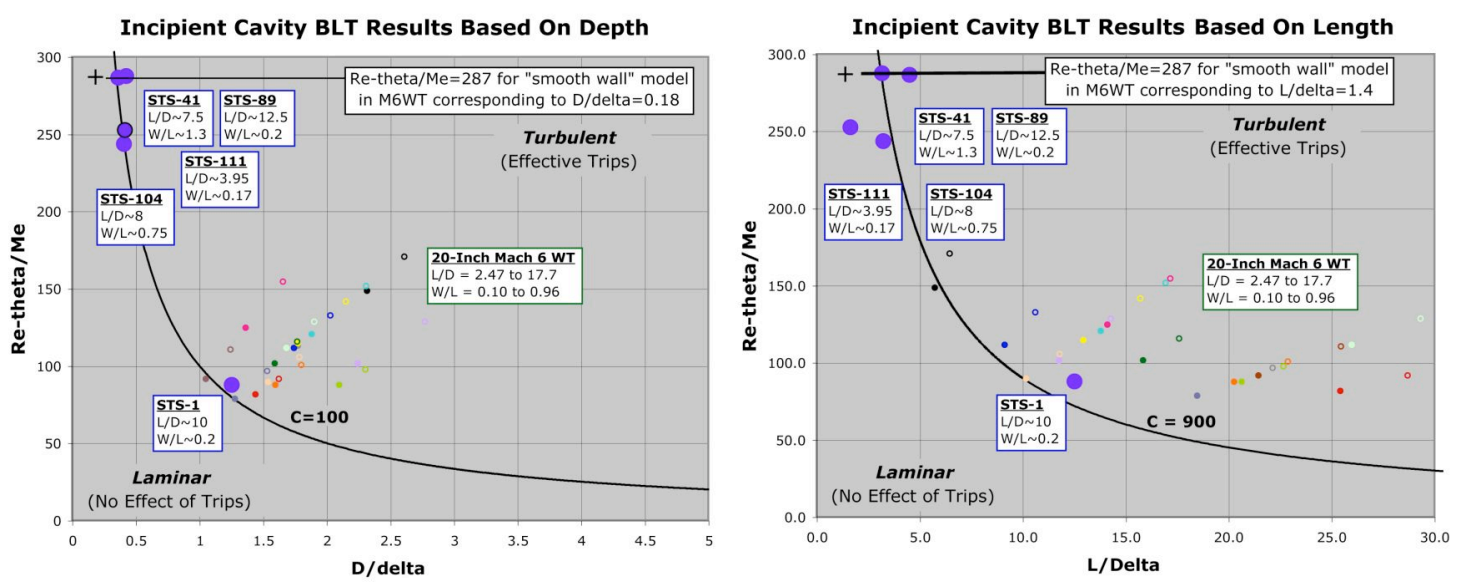

Fig. 15 Cavity correlations used for STS-114

method to infer the actual incipient (first departure from baseline laminar heating) and effective (transition onset within one cavity length) onset Reynolds numbers associated with each individual cavity and angleof-attack. The resulting transition onset map for a short open cavity ( $/ \mathrm{D}=2.47$ ) is shown in Fig. 14 . A value of $(\mathrm{x} / \mathrm{L})_{\mathrm{tr}}$ of 1 signifies that the cavity had no effect and transition onset was not observed on the Shuttle. An $(\mathrm{x} / \mathrm{L})_{\mathrm{tr}}$ value of 0.3 (the cavity site location) signifies a fully effective cavity trip. Any value in between represents a critical case. As shown in Fig. 14, the Reynolds number test point increments were too coarse to use a straight-line approximation to infer the effective values. As with the protuberance transition maps, a smooth curve fairing of the transition map data was used when necessary to better define the incipient and effective transition point Reynolds numbers.

As discussed in Ref. 6, the wind tunnel cavity BLT observations were correlated in the form $\left(\operatorname{Re}_{\theta} / M_{e}\right)(k / \delta)=C$ using a simple engineering-based methods to compute local conditions at the cavity site. In the case of cavities the disturbance parameter $(\mathrm{k} / \delta)$ was based upon either $\mathrm{k}=$ cavity length $(\mathrm{L})$ or $\mathrm{k}=$ cavity depth (D). Based on the review by the technical peer panel and concurrence with the Orbiter Configuration Control Board (OCCB), the cavity BLT correlation used to support STS-114 was based on the LaRC Mach 6 air wind tunnel results and a limited set of flight cavity calibration cases as identified in Fig. 15. A curve coefficient of 100 was used based on cavity depth and 900 based on cavity length, as shown in Fig. 15. Post STS-114, higher Mach number testing has been performed in a reflected shock tunnel (CUBRC) with cavities on a scaled Shuttle model. Additional testing has commenced at LaRC to assess the effects of impact damage shape (non-rectangular) and location (off centerline/pressure gradient) on the existing BLT correlation. In addition, a new correlation disturbance parameter that is based upon cavity volume has been identified and shows promise for future application to the BLT Tool. As this information has not been OCCB certified, it has not been presented.

\section{Ablation}

Approximately 60 wind tunnel runs were performed on 5 SLA resin Orbiter models to determine the effect of an isolated mass injection source on hypersonic boundary layer transition of the windward surface of the Shuttle Orbiter. The objective of the initial testing was to demonstrate test technique capabilities associated with localized blowing and to determine boundary layer transition behavior induced from mass addition into the boundary layer from a small-localized repair site. Estimated blowing rates associated with the ablator

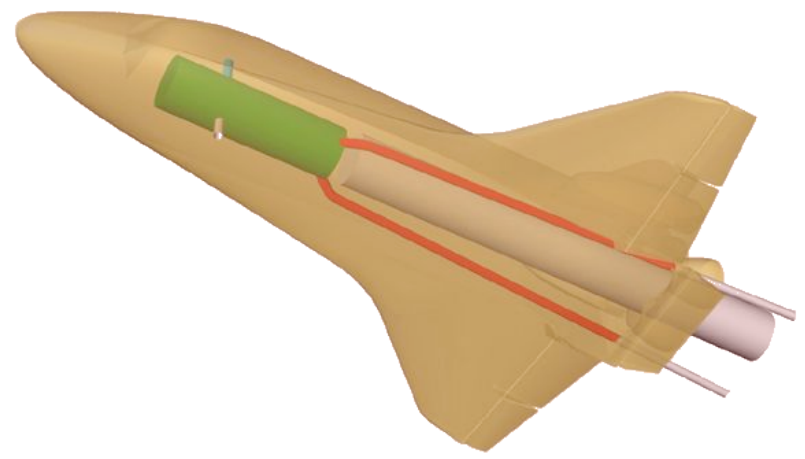

Fig. 16 CAD representation of SLA model with internal gas system for isolated ablation testing 
repair material were used to guide the mass injectant rates. For a majority of the tests, the injected gas was of air; limited tests were performed with $\mathrm{CF}_{4}$ (three times the molecular weight than air) to assess the influence of a heavier molecular weight gas (the expected molecular weight of the pyrolysis products of the proposed ablator repair material was expected to be heavier than air).

The RTF model design strategy for simulating localized ablation was leveraged from a similar process used during the Columbia Accident Investigation ${ }^{60}$ and is illustrated in Fig. 16. The local mass injection source was positioned at a fixed location $(\mathrm{x} / \mathrm{L}=0.3)$ along the model centerline in a region of near zero pressure gradient (consistent with the cavity testing). Sintered metal porous plugs of 40 and 100 media grade were press fit into the resin model at this site. Gas was supplied to the porous plug via a regulator outside the tunnel. A mass flow controller provided up to $1000 \mathrm{sccm}$ flow rate. Downstream of the mass flow controller, tubing led to the test section and the model strut. Flexible metal tubing then provided a connection to one of the tubes extending from the aft end of the model. Out of the second tube from the model, two pressure gauges provided plenum pressure readings throughout the runs. Test parametrics included a fixed angle of attack

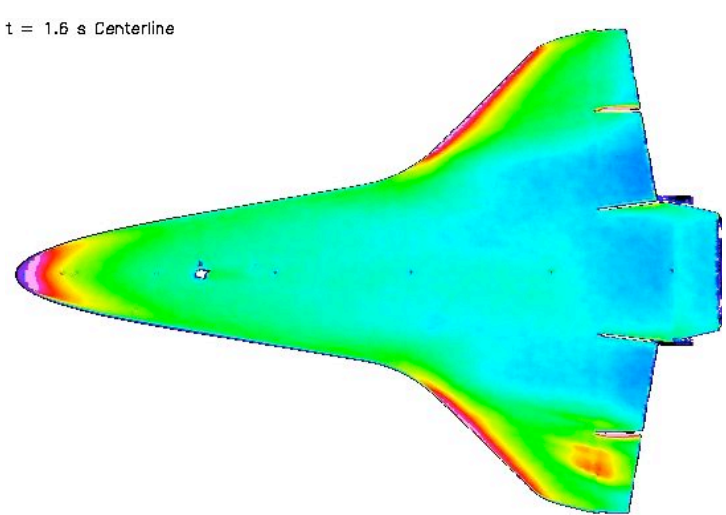

40 media grade porous plug with $0 \mathrm{sccm}$ air

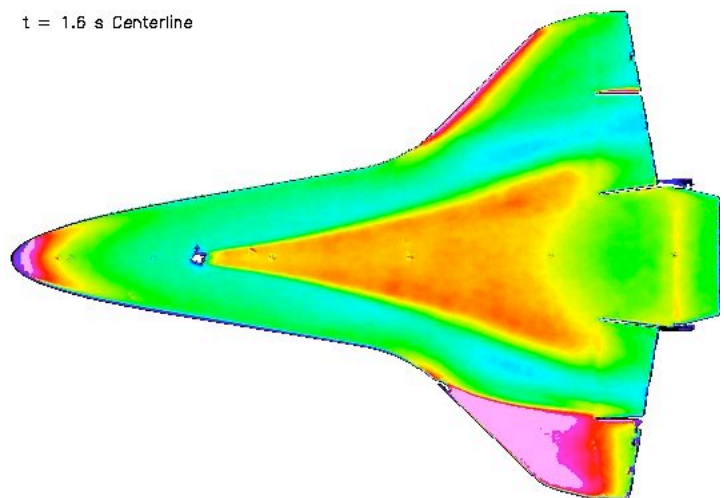

40 media grade porous plug with $1000 \mathrm{sccm}$ air

Fig. 17 Transition from localized mass injection of $40 \mathrm{degs}$, sideslip angle of $0 \mathrm{deg}$, freestream unit Reynolds numbers from $1.1 \times 10^{6}$ to $3.0 \times 10^{6}$, edge-towall temperature ratio of approximately 0.6, and a freestream Mach number of 6 (normal shock density ratio of approximately 5.3).

Transition observations were correlated using the same general approach as with the protuberances and cavities. The transition parameter $\left(\operatorname{Re}_{\theta} / \mathrm{M}_{\mathrm{e}}\right)$ was unmodified. The disturbance parameter was redefined as a mass blowing coefficient $\beta$. The blowing coefficient for this study was defined as the mass flow injected into the boundary layer divided by an effective mass flow through the boundary layer, $\rho_{\mathrm{avg}} \mathrm{U}_{\mathrm{e}} \delta \mathrm{d}$, where $\rho_{\mathrm{avg}}$ is the average of the densities at the wall and at the edge of the boundary layer, $U_{e}$ is the edge velocity, $\delta$ the boundary layer thickness and $d$ is the diameter of the porous plug. All of these quantities were computed at nominal flow conditions using the same engineering methodology in support of the cavity and protuberance correlations. It was later determined that the present blowing coefficient while unconventional, was directly proportional to more traditional methods ${ }^{25}$.

The testing successfully demonstrated the capability of utilizing rapid-prototyped resin models with internal passages to provide local blowing to the windward surface. As anticipated, localized mass injection was shown to promote transition earlier than the corresponding no blowing case, Fig. 17. In these qualitative global heat transfer images, run-to-run differences in the surface roughness of the carbon coating (see model description section) on the Shuttle wing leading edge produced asymmetrical turbulent patterns on the lower wing. The images presented in Fig. 17 were obtained on the same model and unit Reynolds number $\left(3.0 \times 10^{6}\right)$, however progressive loss of phosphors and carbon coating on the wing leading edge was observed run-to-run. The thermal properties of the SLA resin material have not been determined which precluded quantitative measurements of heat transfer. While the detection of temperature increases associated with boundary layer transition was feasible, direct comparison with heating measurements obtained on the ceramic models was not possible. 
No coating loss was observed upstream of the porous plug and reasonable correlation trends were established as shown in Fig. 18. Consistent with protuberance and cavity correlations, an increase in the disturbance parameter (in this case, the blowing coefficient) lowered the value of the transition parameter required to trip the flow from a laminar to a turbulent state. Expected flight ablation rates from the proposed tile ablator concept are an order of magnitude less than those observed to have an effect in the present test results. That is, when the correlated wind tunnel results on the model centerline were compared against the estimated in-flight ablation rates expected from the ablator repair material (near zero), Fig. 18, the blowing coefficient required to initiate transition onset was an order of magnitude larger. A heavier molecular weight injectant gas (believed to be more representative of the out-gassing constituents of the repair material) attenuated transition onset (consistent with observations in Refs. 25, 37). In support of STS-114, it was concluded that localized ablation at the mass flow rates provided to the BLT team should not initiate high Mach number transition. No further testing was performed and the BLT Tool baselined by OCCB for STS-114 did not implement a predictive capability based upon these wind tunnel results. The ablator repair concept has since been replaced by a tile overlay concept (a local protuberance) and no future ablation simulation testing is anticipated.

\section{Summary}

To support the Shuttle RTF effort, a predictive tool was developed for estimating the onset of boundary layer transition from deviations to the OML. The BLT Tool is the first step in the analysis process of the local TPS aerothermodynamics in order to allow informed disposition of damage for making recommendations to fly as is or to repair. Using mission specific trajectory information and details of each damage site or repair, the expected time of transition is predicted to define the proper aerothermodynamic environment to use in the subsequent thermal and stress analysis of the structure. The BLT correlations utilized for the tool were developed from ground-based measurements that have been summarized in this paper. The experimental databases were developed by simulating the surface defects associated with TPS damage and/or repair on scaled wind tunnel models. Using boundary layer edge conditions to correlate the results, specifically the momentum thickness Reynolds number over the edge Mach number and the boundary layer thickness, curve coefficients of 27, 100, and 900 were selected to predict transition onset for protuberances based on height, and cavities based on depth and length, respectively. Testing to simulate the effects of localized ablation indicated that while transition was promoted by local surface blowing, the required blowing rates from the present tests were an order of magnitude higher than estimated for the ablator repair concept. In addition, a heavier molecular weight gas (believed to be more representative of the out-gassing constituents of the repair material) was shown to attenuate boundary layer transition.

\section{Acknowledgments}

Without the assistance of the following individuals this work would not have been possible: Gary Wainwright, Mike Powers, Mark Griffith, and John Hopkins, Ed Covington, Pete Veneris, and Kathy Kuykendoll, for model design, fabrication, instrumentation, and surface inspection support; John Ellis, Rhonda Manis, Roland Hatten, Teck-Seng Kwa, Grace Gleason, Glen Bittner, Melanie Lawhorne, Christal Kellam, Harry Stotler, Henry Fitzgerald, and Kevin Hollingsworth for wind-tunnel support; Sheila Wright and Bert Senter for data acquisition assistance; Chuck Campbell, Jerry Kinder, and Dan Reda, for analysis support; Frank Green, Bill Wood, Harris Hamilton, and James Reuther for CFD support; Joe Haney, Sun Hong, Roger Kimmel, David Kuntz, Anthony Martellucci, John Schmisseur, Vince Zoby, Kathryn Wurster, and Steve Labbe for support to the RTF Boundary Layer Transition Peer Review Panel; and Richard Wheless for documentation assistance. The authors gratefully acknowledge their contributions and behindthe- scenes work. 


\section{$\underline{\text { References }}$}

${ }^{1}$ Columbia Accident Investigation Board Final Reports, Vols. I-VI [online resource], URL: http://caib.nasa.gov/ [cited Aug and Oct 2003].

${ }^{2}$ Hale, N. W., Lamotte, N. O., and Garner, T. W., "Operational Experience with Hypersonic flight of the Space Shuttle," AIAA -2002-5259, Sept., 2002.

3 Bouslog, S. A., An, M. Y., and Derry, S. M., "Orbiter Windward Surface Boundary Layer Transition Flight Data," NASA CP-3248, Orbiter Experiments (OEX) Aerothermodynamics Symposium, April 1995, pp. 703-739.

${ }^{4}$ Goodrich, W. D., Derry, S. M., and Bertin, J. J., "Shuttle Orbiter Boundary Layer Transition at Flight and Wind Tunnel Conditions," Shuttle Performance: Lessons Learned, Part 2, NASA CP 2283, March 1983, pp. 753-779.

5 Campbell, C. H., Anderson, B., Bourland, G., Bouslog, S., Cassady, A., Horvath, T., Berry, S., Gnoffo, P., Wood, B., Reuther, J., Driver, D., Chao, D., and Picetti, D., “Orbiter Return To Flight Entry Aeroheating,” AIAA-2006-2917, June 2006.

${ }^{6}$ Berry, S. A., Horvath, T. J., Greene, F. A., Kinder, G. R., and Wang, K. C., "Overview of Boundary Layer Transition Research in Support of Orbiter Return To Flight,” AIAA-2006-2918, June 2006.

${ }^{7}$ Greene, F. A., and Hamilton, H., "Development of a Boundary Layer Properties Interpolation Tool in Support of Orbiter Return-To-Flight,” AIAA-2006-2920, June 2006.

${ }^{8}$ McGinley, C., Berry, S. A., Kinder, G. R., Barnwell, M., Wang, K. C., and Kirk, B. S., "Review of Orbiter Flight Boundary Layer Transition Data," AIAA-2006-2921, June 2006.

${ }^{9}$ Berry, S. A., Horvath, T. J., Cassady, M. A., Kirk, B. S., Wang, K.C., and Hyatt, A. J., "Boundary Layer Transition Results From STS-114,” AIAA-2006-2922, June 2006.

10 Berry, S. A., and Hamilton, H. H., "Discrete Roughness Effects on Shuttle Orbiter at Mach 6," AIAA Paper 20022744, June. 2002.

11 Berry, S. A., Bouslog, S. A., Brauckmann, G. J., and Caram, J. M., "Shuttle Orbiter Experimental Boundary-Layer Transition Results with Isolated Roughness," Journal of Spacecraft and Rockets, Vol. 35, No. 3, 1998, pp. 241-248.

12 Bouslog, S. A., An, M. Y., Campbell, C. H., Wang, K. C., and Pelley, R. L., "Orbiter Boundary-Layer Transition Working Group: Analysis and Ground Test Status Report,” NASA Johnson Space Center, JSC-26812, Oct. 1994.

${ }^{13}$ Batt, R. G., and Legner, H. H., “A Review of Roughness-Induced Nosetip Transition,” AIAA Journal, Vol. 21, No. 1, Jan. 1983, pp.7-22.

${ }^{14}$ Van Driest, E. R., and Blummer, C. B., "Boundary Layer Transition on Cones and Spheres at Supersonic Speeds Effects of Roughness and Cooling,” U.S. Air Force Office of Scientific Research, Report 67-2048, July 1967.

15 Berkowitz, A. M., Kyriss, C. L., and Martellucci, A., "Boundary Layer Transition Flight Test Observations,” AIAA Paper 77-125, Jan. 1977.

${ }^{16}$ Boudreau, A. H., "Artificially Induced Boundary-Layer Transition on Blunt-Slender Cones at Hypersonic Speeds," Journal of Spacecraft and Rockets, Vol. 16, No. 4, 1979, pp. 245-251.

${ }^{17}$ Pate, S. R., "Dominance of Radiated Aerodynamic Noise on Boundary-Layer Transition in Supersonic-Hypersonic Wind Tunnels," Arnold Engineering Development Center, TR-77-107, Arnold Air Force Station, TN, March 1978.

18 Dirling, R. B. Jr., Swain, C. E., and Stokes, T. R., "The Effect of Transition and Boundary Layer Development on Hypersonic Reentry Shape Change,” AIAA Paper 75-673, May 1975.

${ }^{19}$ Stetson, K. F., "Boundary-Layer Transition on Blunt Configurations," NASA Johnson Space Center, JSC-26528, Feb. 1994.

20 Reda, D. C., "Review and Synthesis of roughness-Dominated Transition Correlations for Reentry Applications," Journal of Spacecraft and Rockets, Vol. 39, No. 2, pp. 161-167. 
21 Goodrich, W. D., Derry, S. M., and Bertin, J. J., "Shuttle Boundary Layer Transition at Flight and Wind Tunnel Conditions," Shuttle Performance: Lessons Learned, Part 2, NASA CP 2283, March, 1983, pp. 753-779.

${ }^{22}$ Charwat, A. F., Roos, J. N., Dewey, C. F., Jr., and Hitz, J. A., “An Investigation of Separated Flows-Part I: The Pressure Field,” Journal of Aerospace Sciences, Vol. 28, No. 6, June 1961, pp. 457-470.

${ }^{23}$ Charwat, A. F., Dewey, C. F., Roos, J. N., Jr., and Hitz, J. A., “An Investigation of Separated Flows-Part II: Flow in the Cavity and Heat Transfer,” Journal of Aerospace Sciences, Vol. 28, No. 7, July 1961, pp. 513-527.

24 Nestler, D. E., “The Effects of Surface Discontinuities on Convective Heat Transfer in Hypersonic Flow," AIAA Paper 85-0971, June. 1985.

${ }^{25}$ Ginoux, J. J, Thiry, F., “Cone Cavity Flow at Mach 5.3 with Injection of Light, Medium, and Heavy Gas,” Technical Report VKI TN 35, AFOSR Final Report 69-0618, Von Karman Institute for Fluid Dynamics, November, 1968. DTIC Citation AD681533.

${ }^{26}$ Ginoux, J. J, "Laminar Separation in Supersonic and Hypersonic Flows,” Technical Report VKI TN 35, AFOSR Final Report 67-0615, Von Karman Institute for Fluid Dynamics, September, 1966. DTIC Citation AD6647819.

27 Scherrer, R., "Boundary-Layer Transition on a Cooled 20-deg. Cone at Mach Numbers of 1.5 and 2.0," Technical Note 2131, NACA, July 1950.

${ }^{28}$ Carver, D.B., "Heat Transfer Tests on the Rockwell International Space Shuttle Orbiter with Boundary-Layer Trips (OH-54),” Technical Report AEDC-TR-76-28, AEDC, May 1976.

${ }^{29}$ Larson, H. K., and Keating, S. J., Jr. "Transition Reynolds Numbers of Separated Flows at Supersonic Speeds," Technical Report NASA TN-D-349, NASA, December 1960.

30 King, R. A., Creel, T. R. Jr., and Bushnell, D. M., "Experimental Transition Investigation of a Free-Shear Layer Above a Cavity at Mach 3.5,” Journal of Propulsion, 1991, pp. 626-634.

${ }^{31}$ Hahn, M., "Experimental Investigation of Separated Flow Qver a Cavity at Hypersonic Speed,” AIAA Paper 68-672, June 1968.

32 Morrisette, L. E., Effect of Mass Injection Into a Cavity on Hypersonic Boundary-Layer Transition." AIAA Journal, Vol. 4. No. 8, August 1966, pp. 1488-1489.

33 Wood, W. A., Pulsonetti, M.V., Everhart, J.L., and Bey, K.S., “Assessment of LAURA for Laminar Supersonic Shallow Cavities. AIAA Paper 2004-2639, June 2004.

34 Cheatwood, F. M., Merski, N. R., Riley, C.J., and Mitcheltree, R.A., “Aerothermodynamic Environment Definition for the Genesis Sample Return Capsule. AIAA Paper 2001-2889, June 2001.

35 Wood, W. A., Pulsonetti, M.V., Everhart, J.L., and Bey, K.S., “Assessment of LAURA for Laminar Supersonic Shallow Cavities. AIAA Paper 2004-2639, June 2004.

36 Hollis, B.R., Liechty. D.S., "Boundary-Layer Transition Correlations and Aeroheating Predictions for Mars Smart Lander,” AIAA Paper 2002-2745, June 2002.

37 Stalmach, C. J., Jr., Bertin, J.J., Pope, T.C., and McCloskey, M.H., “A Study of Boundary Layer Transition on Outgassing Cones in Hypersonic Flow,” Technical Report NASA-CR-1908, December 1971.

${ }^{38}$ Dunavant, J. C., and Everhart, P. E., "Exploratory Heat-Transfer Measurements at Mach 10 on a 7.5-deg. Total-Angle Cone Downstream of a Region of Air and Helium Transpiration Cooling," NASA Technical Note TN-D-5554, December 1969.

39 Lin, T.C., "Development of the U.S. Air Force Intercontinental Ballistic Missile Weapon Systems. Journal of Spacecraft and Rockets, Vol. 40, No. 4, July-August 2003, pp. 491-509.

40 Moss, J. N., and Simmonds, A. L., "Galileo Probe Forebody Flow-field Predictions, "Entry Vehicle Heating and Thermal Protection System: Space Shuttle, Solar Star Probe, Galileo Probe," Progress in Astronautics and Aeronautics, ed. PE Eaver, HE Collicoft, Vol. 85, pp. 419-445, 1983. 
41 Berry, S. A., Nowak, R. J., and Horvath, T. J., "Boundary Layer Control for Hypersonic Airbreathing Vehicles," AIAA Paper 2004-2246, June, 2004.

42 Buck, G. M., Powers, M. A., Griffith, M. S., Hopkins, J. W., Veneris, P. H., and Kuykendoll, K. A., "Fabrication of 0.0075-Scale Orbiter Phosphor Thermography Test Models for Shuttle RTF Aeroheating Studies," NASA TM2006-214303, May 2006.

43 Miller, C. G., "Langley Hypersonic Aerodynamic/Aerothermodynamic Testing Capabilities - Present and Future," AIAA Paper 90-1376, June 1990.

44 Chokani, N., Shipluk, A. N., Sidorenko, A. A., and McGinley, C. B.,"Comparison Between a Hybrid ConstantCurrent Anemometer and Constant-Voltage Anemometer in Hypersonic Flow," AIAA Paper 2004-2248, June, 2004.

45 Poll, D. I., "Laminar-Turbulent Transition,” AGARD Advisory Report 319, Vol.1, 1996.

46 Schneider, S. P., "Effects of High-Speed Tunnel Noise on Laminar-Turbulent Transition," J. of Spacecraft and Rockets, Vol. 38, no. 3, May-June 2001, pp. 323-333

47 Dietz, A. J., "Boundary-Layer Receptivity to Transient Convected Disturbances" AIAA Journal, Vol. 36,No. 7, July, 1998.

48 Buck, G. M., “Automated Thermal Mapping Techniques Using Chromatic Image Analysis,” NASA TM 101554, April 1989.

49 Merski, N. R., "Reduction and Analysis of Phosphor Thermography Data With the IHEAT Software Package," AIAA Paper 98-0712, Jan. 1998.

50 Merski, N. R., "Global Aeroheating Wind-Tunnel Measurements Using Improved Two-Color Phosphor Thermography Method” Journal of Spacecraft and Rockets, Vol. 36, No. 2, 1998, pp. 160-170.

51 Horvath, T. J., Berry, S. A., Merski, N. R., and Fitzgerald, S. M., "X-38 Experimental Aerothermodynamics," Journal of Spacecraft and Rockets, Vol. 41, No. 2, 2004, pp. 272-292.

${ }^{52}$ Horvath, T. J., Berry, S. A., Hollis, B.R., Liechty, D.S., and Merski, N. R., "X-33 Experimental Aeroheating at Mach 6 Using Phosphor Thermography," AIAA Paper 99-3558, June, 1999.

53 Gnoffo, P. A., “An Upwind-Biased, Point-Implicit Relaxation Algorithm for Viscous Compressible Perfect-Gas Flows,” NASA TP-2953, 1990

54 Hamilton II, H. H., Millman, D. R., and Greendyke, R. B., "Finite-Difference Solution for Laminar or Turbulent Boundary Layer Flow Over Axisymmetric Bodies With Ideal Gas, $\mathrm{CF}_{4}$, or Equilibrium Air Chemistry," NASA TP3271, Dec. 1992.

55 Poll, D. I. A., "Boundary Layer Transition on the windward Face of the Space Shuttle During Re-Entry," AIAA Paper 1985-0899, June, 1985.

56 Berry, S. A., Horvath, T. J., Hollis, B. R., Thompson, R. A., and Hamilton II, H. H., "X-33 Hypersonic Boundary Layer-Transition,” Journal of Spacecraft and Rockets, Vol. 38, No. 5, 2001, pp. 646-657.

57 Fischer, M. C., “Spreading of a Turbulent Disturbance," AIAA Journal, Vol. 10, No. 7, July 1972, pp.957-959.

58 Liechty, D. S., Berry, S. A., and Horvath, T. J., "Shuttle Return To flight Experimental Results: Protuberance Effects on Boundary Layer Transition," NASA TM-2006-214306, May 2006.

${ }^{59}$ Liechty, D. S., Horvath, T. J., and Berry, S. A., "Shuttle Return To flight Experimental Results: Cavity Effects on Boundary Layer Transition,” NASA TM-2006-214305, May 2006.

60 Horvath, T. J., "Experimental Aerothermodynamics In Support of the Columbia Accident Investigation," AIAA Paper 2004-1387, June, 2004. 